\title{
Bidder hubris and founder targets
}

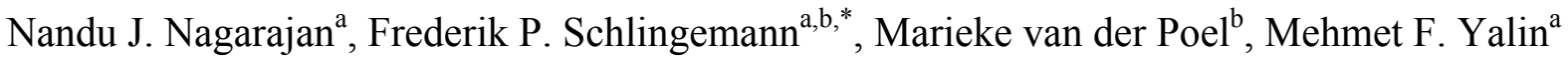 \\ ${ }^{a}$ Katz Graduate School of Business, University of Pittsburgh, Pittsburgh, PA 15260, USA \\ ${ }^{\mathrm{b}}$ Rotterdam School of Management, Erasmus University, Rotterdam, 3062 PA, Netherlands
}

December 2013

\begin{abstract}
Overpayment for acquisitions can occur if managerial hubris leads bidders to overestimate target standalone values under their control. We provide a unique test of this phenomenon by analyzing whether bidders overpay for founder CEO targets because they overestimate their ability to replicate the value of the founder CEOs' firm-specific human capital post-acquisition. We show that the founder CEOs' human capital is valuable and embedded in the ex-ante targets' value and is, economically and statistically, negatively associated with bidder gains and synergy returns. Our findings are consistent with bidders' overestimating the value of founder CEO targets as stand-alone firms under their control.

JEL classification: G30; G34

Keywords: Hubris; founder; bidder gains; mergers and acquisitions; CEO

\footnotetext{
is We thank Khaled Abdou, Leonce Bargeron, David Becher, Dave Denis, Diane Denis, Harry Evans, Jana Fidrmuc, Michelle Lowry, Sara Moeller, Henry Manne, Harold Mulherin, Marios Panayides, Annette Poulsen, Raghu Rau, Harley "Chip" Ryan Jr, René Stulz, Marno Verbeek, Ralph Walkling, David Yermack, and the conference and seminar participants at the 2012 Midwest Finance Association Annual Meeting, the 2012 Florida State SunTrust Beach Conference, the 2012 Drexel University Academic Conference on Corporate Governance, the 2012 Financial Management Association Annual Meeting, the program committee of the 2013 Paris Finance Meeting EUROFIDAI for including the paper on their program, the European School of Management and Technology (ESMT), the Rotterdam School of Management (RSM), the University of Connecticut, and Warwick University for valuable comments. Ahmet Kurt, Yvonne Chu and Hailu Jiang provided excellent research assistance.

* Corresponding author. Tel.: +412-648-1847; fax: +412-648-1693.

Email address: schlinge@katz.pitt.edu (F.P. Schlingemann)
} 
"A lot of entrepreneurs dream of the big exit: That the company they set up, nurtured and raised will one day be bought by someone else, showering them with riches and maybe allowing them to move on to The Next Big Thing.” [Ben Rooney, Wall Street Journal, October 25, 2012]

\section{Introduction}

A large literature on acquisitions documents significant negative abnormal returns to acquiring firm shareholders when they make substantial acquisitions of public companies. For example, Andrade et al. (2001) report that acquirer shareholders, on average, lost $3.8 \%$ in shareholder wealth between the announcement and the completion of 4,256 deals announced between 1973 and 1998. ${ }^{1}$ While the debate is ongoing about whether acquisitions, on average, destroy value and what the role played by sample criteria is in arriving at this conclusion (e.g., Netter et al., 2011), the evidence clearly indicates that there is extensive cross-sectional variation in both bidder and synergy returns (e.g., Fuller et al., 2002).

One explanation for the variation in both bidder and synergy returns, initially proposed by Roll (1986), is that managerial hubris causes some bidders to overpay for acquisition targets and, thus, the bids we observe include positive valuation errors. ${ }^{2}$ In particular, overpayment can come from two nonmutually exclusive sources: (i) overestimation of the target's stand-alone value under the bidder's control, and/or (ii) overestimation of the synergies that can be achieved by combining the bidder and target firms. ${ }^{3}$

We provide a unique empirical test of the first source of overestimation by analyzing whether bidders pay for some specialized resource embedded in the ex-ante value of the target firm, oblivious to any concern that this resource could be expected to diminish in value ex post. Such bidders, if infected by hubris, could optimistically assume that their own ability to generate value substitutes for the diminished or dissipated value of this specialized resource. Thus, even though bidders may be aware ex ante of the

\footnotetext{
${ }^{1}$ See also, e.g., Asquith et al.,1983; Chang, 1998; Fuller et al., 2002; Moeller et al., 2004 and 2007; Servaes, 1991; Travlos, 1987.

${ }^{2}$ Specifically, Roll (1986, p.213) writes "Hubris predicts that, around a takeover, (a) the combined value of the target and bidder firms should fall slightly, (b) the value of the bidding firm should decrease, and (c) the value of the target should increase."

${ }^{3}$ Hietala et al. (2003) argue that it is often impossible to isolate the different effects embedded in the market reaction associated with information about potential synergies in the bidder-target combination, the stand-alone value of the target, and the amount of bidder overpayment.
} 
value of this specialized resource, their hubris may lead them to believe that they can recreate or find substitutes for its value once the merger is consummated.

The specialized resource we consider in this paper is the human capital of founder CEOs. Specifically, based on findings in the literature and our own analysis, we argue that the presence of a founder CEO contributes in an economically and statistically significant way to the ex-ante value of the target firm. Yet, the value of this resource, insofar as it is unique to the founder, is likely to diminish or disappear following the acquisition because the founder often departs post acquisition, or may be less motivated or unable to generate similar value in any post-acquisition role with the combined firm. Consequently, at least part of this ex-ante founder value the bidder paid for would not be available in its original form or be replicable by the bidder. In other words, by overestimating their ability to substitute for the value of the founder CEOs' firm-specific human capital, managerial hubris would lead bidders to overestimate what the target's value would be as a stand-alone entity under their control. We label this the valuable founder hypothesis. An implication of the valuable founder hypothesis is that an ex-ante measure of the founder CEO's human capital can serve as a proxy for the bidder's overpayment arising from hubris and thus, is expected to be negatively associated with bidder gains.

Roll's (1986) theory of hubris also makes specific predictions with respect to the combined value of the target and bidder firms (synergy returns). The total synergy reflects the difference between the operating synergy obtained from combining the two firms and the decline in the stand-alone value of the target arising from the loss of the founder CEO's human capital. Consequently, the valuable founder hypothesis also predicts that the founder CEOs' human capital would be negatively associated with synergy returns.

An important assumption underlying the valuable founder hypothesis is that the founder CEO's human capital positively affects firm value. Villalonga and Amit (2006), Palia et al. (2008), Fahlenbrach (2009), and Li and Srinivasan (2011) all use treatment models to provide evidence that the founder's 
presence positively affects firm value and performance. ${ }^{4}$ One potential explanation for the value that founder CEOs bring to their firms is that founder CEOs, having substantial ownership stakes in their firms, are likely to focus on value-creating strategies to ensure that their personal investment in their firms is not jeopardized (Fahlenbrach, 2009). Further, as Fahlenbrach (2009, p. 440) points out, founder CEOs are likely to have strong intangible associations with their firms that result in 'intrinsic motivation' to assure their firms' success. Bidders, however, face the problem that the founder CEO would likely not pursue the same strategies or have the same decision rights post-acquisition as he may have had preacquisition. ${ }^{5}$ Thus, the intangible and tangible benefits that founder CEOs bring to the table could be fully or partially lost when these firms are acquired. While it may seem this loss would be especially pertinent if the founder CEO leaves after the transaction, the question we address is also relevant to cases wherein the founder CEO is retained by the bidder. Typically, retained CEOs assume a managerial or advisory role with substantially reduced decision rights. In other words, according to our valuable founder hypothesis, any reduction in a founder CEO's post-acquisition added value should lead to overpayment due to the bidder's overestimation of the substitutability of this specialized resource.

Analyzing the role of the founder CEO's human capital as a valuable resource has a number of important benefits. First, the value a founder CEO contributes to his firm is an example of a specialized resource that is easily identifiable and has been established in the literature. Second, focusing on firmlevel measures of human capital allows for cross-sectional analysis and does not rely on a bidder "overpaying for the acquisition" overall, but rather overpaying for a specialized resource, whose value is embedded in the target price. Hence, our tests do not depend on whether average bidder returns are

\footnotetext{
${ }^{4}$ Further emphasizing the unique human capital that founders bring to the firm, there is also growing evidence (Villalonga and Amit, 2006; Pérez-González, 2006; Bertrand et al., 2008, for Thai firms) that founder control of firms is associated with higher values, but this declines when the firms are passed on to succeeding generations of family members.

${ }^{5}$ The Wall Street Journal (October 25, 2012) reports in an article titled, "Assessing the Lure of the Big Exit" that founders of targets may have more limited responsibilities following the acquisition. The article states, "Going from CEO of your own company to being a part of someone else's organizational chart brings with it a whole new set of issues, like meeting your boss for the first time." The article also quotes a target founder as saying, "When you go and have your first meeting with your new boss, in all honesty, you are a bit nervous and you wonder what that person is going to be like."
} 
negative or positive, which may be unrelated to the bidder overpaying for the target's assets. Negative bidder returns, for example, could result from the market learning about limited internal growth opportunities (e.g., Jovanovic and Braguinsky, 2004; McCardle and Viswanathan, 1994). Similarly, a positive bidder return does not necessarily mean that the bidder did not overpay for a specific part of the target's assets. Third, the stand-alone value of the target firm is likely to be impacted because the founder CEO's human capital is expected to exhibit a discrete change following the acquisition. Fourth, takeover bids are often a major decision for the bidding firm and present an important opportunity for shareholder wealth effects for both the acquirer and the target.

To test the valuable founder hypothesis we estimate a treatment model, where the treatment is the presence of a founder CEO in the target. Specifically, we use an endogenous switching model to estimate the firm-specific value of the founder CEO's human capital, which reflects the part of the target's ex-ante value (Q) that can be explicitly attributed to the presence of a founder CEO. In order to do so, we first estimate a firm-level hypothetical measure of value for each target with a founder CEO as if it were a non-founder target. The switching model allows for consideration of differences in firm and CEO characteristics across targets with a founder CEO and targets without a founder. Allowing for heterogeneity is important and yields specific projections determined by the switch between targets with a founder $\mathrm{CEO}$ and targets without a founder, reducing concerns that the relation between the firm-specific value of the founder CEO's human capital and bidder gains is driven by some non-linear relationship between firm characteristics and their performance. We isolate the value of the target attributable to the founder CEO's presence by subtracting the hypothetical firm value from the actual firm value. This measure represents our estimate of the value of the founder CEO's human capital (FHC). The valuable founder hypothesis predicts a negative association between FHC and bidder or synergy returns.

Using a sample of 845 acquisitions between 1997 and 2008, we report the following main findings in support of the valuable founder hypothesis: 
1. For our sample of takeover targets, using ordinary least squares, treatment, and a matching estimator, we show that the founder CEOs' human capital is valuable and embedded in the exante target value. This finding is consistent with the founder CEO effects reported in Villalonga and Amit (2006), Fahlenbrach (2009), and Li and Srinivasan (2011), each of whom analyzes more generic samples of founder firms.

2. Using a binary variable to indicate whether the target CEO is the founder or not, we find weak evidence of lower bidder gains for acquisitions that involve targets with a founder CEO compared to acquisitions of targets without a founder.

3. Both bidder gains and synergy returns exhibit a strong negative correlation with the firm-specific value of the founder CEO's human capital (FHC). The impact of FHC on bidder gains and synergy returns is both economically large and statistically strong. For example, a one standard deviation increase in FHC results in a decrease in bidder gains of 1.63 percentage points. Also, while the part of Tobin's Q explained by the founder CEO's presence (i.e., the founder effect) is significantly negatively correlated with bidder returns, the target's Tobin's Q unexplained by the founder CEO's presence is unrelated to bidder or positively related to synergy returns.

4. The negative relation between bidder returns and FHC persists when the founder CEO departs the acquirer within two years after the completion of the takeover, but not when the CEO is retained for two years or more.

We reject a number of alternative explanations for our results and perform additional robustness tests. For example, our findings could be attributed to the founder's potentially superior bargaining power on behalf of his shareholders. In other words, founders may have a superior ability to exert control over the transaction and extract a higher price from the bidder. However, we find no relation between our 
proxy for founder human capital (FHC) and measures of target premiums or the relative share of the total gains captured by the target. ${ }^{6}$

Another interpretation of our results is that founder CEOs may have larger private benefits of control than non-founder CEOs and as such, have a higher hurdle to accept a takeover bid. Accepting a bid may then be viewed as a classic 'lemons problem' in which the founder CEO, relative to a nonfounder CEO, has superior private information about his firm's lack of prospects. That is, the founder CEO, who enjoys control of his firm is only willing to tender control of it because its prospects are poor, thereby resulting in the acquisition being viewed as a negative signal by bidder shareholders. However, it seems unlikely that the founder CEO's private information regarding the firm's lack of prospects is correlated with FHC. In fact, while we find a negative association between FHC and bidder returns, the relation between the founder CEO indicator variable and bidder returns becomes insignificant when we control for FHC in our regressions. Moreover, we find that our results hold irrespective of whether the bidder or target initiates the deal.

This paper contributes to several strands of the literature in corporate finance. A large literature exists on bidder returns with many papers addressing the issue of overconfidence and overpayment by public bidders when they acquire public targets (see e.g., Roll, 1986; Black, 1989, for earlier work and Moeller et al., 2004, 2005; Malmendier and Tate, 2008; Bargeron et al., 2008; Lee and Malmendier, 2011; Baker et al., 2012, for more recent work). However, our paper is, to the best of our knowledge, the first that attempts to isolate the founder CEO's human capital at the firm level and tests whether the market perceives this specialized resource unique to the target as a source for overpayment. In particular, we identify the ex-ante founder CEO's human capital as a specific value resource within the target that can easily be identified and quantified and is expected to exhibit a discrete change after the acquisition.

\footnotetext{
${ }^{6}$ We acknowledge that we may falsely reject the bargaining alternative if we primarily observe deals in which the founder CEO bargains primarily for personal gain rather than on behalf of the target's shareholders because this would not necessarily lead to the predicted increase in the target relative gains (see e.g., Moeller, 2005). However, the target's founder bargaining for personal gain would potentially benefit the acquirer in terms of facilitating the deal and, therefore, would not offer an alternative to our valuable founder hypothesis which predicts a negative relation between FHC and bidder gains.
} 
The paper also adds to a growing literature on CEO characteristics and their association with firm value and performance (Kaplan et al., 2012). Finally, the paper furthers our understanding of the role founders play in the governance structure of firms and provides evidence that founder CEOs are associated with increased firm value in a sample of takeover targets.

The remainder of the paper continues as follows. In Section 2, we introduce the sample design and present descriptive statistics. Section 3 establishes an average founder effect in the sample and Section 4 presents the endogenous switching model we use for estimating firm-level measures of the exante value of the founder CEO's human capital (FHC) and tests of the valuable founder hypothesis. Section 5 discusses alternative interpretations and a variety of robustness issues. Section 6 concludes the paper.

\section{Sample design and descriptive statistics}

\subsection{Sample design}

In our sample design, we consider the following two issues: first, our valuable founder hypothesis builds on the literature that shows the presence of a founder premium. Most notably, the papers we follow are Villalonga and Amit (2006), Fahlenbrach (2009), and Li and Srinivasan (2011). Each of these papers considers relatively large firms and uses panel data. ${ }^{7}$ Given that we focus on acquisition events, we cannot use panel data; however, we do focus on larger target firms to stay close to the existing literature on the founder premium. Second, while Netter et al. (2011) have shown that sample selection criteria play an important role when drawing conclusions about average valuation effects of takeovers, our main goal is to explain part of the cross-sectional variation in bidder gains and synergy returns within our selection criteria. While we do not claim that our results apply to each and every possible type of acquisition, we show that within a sample of founder-run acquisition targets a significant average founder effect exists

\footnotetext{
${ }^{7}$ Fahlenbrach (2009) and Li and Srinivasan (2011) both use the IRRC directors database, which is based on S\&P 1500 firms, and Villalonga and Amit (2006) uses Fortune 500 firms.
} 
and that bidder and synergy returns are negatively correlated with a firm-specific measure of this founder effect. Details about the criteria used for the sample follow.

We collect the merger and acquisition sample from the Thomson-Reuters Securities Data Corporation (SDC) database. In order to keep the hand-collecting of essential CEO and company data manageable, we focus on bidders included in the S\&P 1500, but do not impose this constraint on the targets. We include all completed deals announced between the calendar years 1997 and 2008 . We require both the acquirer and target to be listed on a public stock exchange and headquartered in the U.S. The acquirer should own at most $50 \%$ of the target before the announcement. ${ }^{8}$ Similar to Cai and Vijh (2007) and Bargeron et al. (2008), we require that after the completion of the deal, the acquirer must fully own the target. We next match the set of acquirers with the Center for Research on Securities Prices (CRSP) and the Compustat Fundamentals Annual (Compustat) databases to collect the return and accounting variables. Since we focus on bidder gains, require detailed information regarding founder status, CEO retention, and other governance variables, and aim to alleviate concerns about takeover anticipation, we require that the events are material. Therefore, we select targets with a book value of assets (BVA) of at least $\$ 100$ million and require BVA of the target relative to BVA of the bidder to be at least $1 \%{ }^{9}$ Notwithstanding this size constraint, the median and mean BVAs are comparable to the numbers reported in Fahlenbrach (2009), but are smaller than those reported for the samples used by Villalonga and Amit (2006) or Li and Srinivasan (2011). When we repeat our tests using a less restricted sample, where we drop the target size restriction to a deal value of $\$ 1$ million, as reported by the SDC, we find that our main results continue to hold. We focus on book values in our selection criteria here, because market values

\footnotetext{
${ }^{8}$ Less than two percent of the final sample concerns deals where the acquirer has a non-zero minority stake (toehold) prior to the deal announcement. All results and conclusions in the paper hold regardless of whether we exclude these from the sample or whether we include binary or continuous variables to measure the toehold and add these either as control variables or interaction variables with our variables of interest.

${ }^{9}$ Alternatively we use a cutoff of $\$ 100$ million based on deal value reported by SDC and $1 \%$ based on the target's market value of assets (MVA) relative to the bidder's MVA, where the market value of assets is defined as the market value of equity plus the book value of assets minus the book value of equity and the deferred taxes. The results are not sensitive to these alternative cutoffs.
} 
may be inflated based on the founder effect and we do not wish to have this issue conflict with our sample selection process.

We collect the CEO's founder status, age, tenure, and cash flow and voting rights from webbased search engines, proxy statements, and merger documents. ${ }^{10}$ To determine whether the CEO is a founder, we check the identity of the company's founder(s) against the information in the company's proxy statement closest to but before the announcement date. We classify the company as having a "founder CEO" if the founder holds the CEO position. We identify 103 companies that have a founder director, but where he does not hold the CEO position. We exclude these observations because the decision rights of founder directors are not comparable to those of founder CEOs. ${ }^{11}$ We classify the company as "non-founder" if no founder is present, either in the CEO position or a director position. ${ }^{12}$ These criteria yield a dataset of 845 observations, where 142 targets are classified as "founder CEO" firms and 703 targets as "non-founder" firms in our final sample.

Andrade et al. (2001) argue that statistically, the most reliable evidence on whether acquisitions create shareholder value comes from using traditional short-window event studies. For each acquisition, we compute cumulative abnormal returns (CAR) using market model-adjusted abnormal returns based on the CRSP value-weighted index for the bidder, the target, and the value-weighted combination of the bidder and the target, which we refer to as the synergy return. Following the definition in Bradley et al. (1988), we measure synergy returns as the bidder market capitalization one month prior to announcement times the bidder CAR plus the target market capitalization one month prior to announcement times the target CAR divided by the sum of the bidder and target market capitalizations one month prior to announcement. Market model parameters are estimated from trading day -379 to trading day -127

\footnotetext{
${ }^{10} \mathrm{We}$ are grateful to Rüdiger Fahlenbrach for sharing his dataset with founder information, which includes the S\&P 1500 firms, even though in his paper he only relies on the S\&P 500 firms. Fahlenbrach (2009) uses proxy statements, Hoover's reports and Dow Jones Interactive Service news in order to identify founder CEO companies. CEOs who took over the company through a management or a leveraged buyout or who are descendants of founders do not qualify as founder CEO companies. Based on his dataset, we are able to find the data on founder status and inception year for 334 observations.

${ }^{11}$ We also run our analyses after including the 103 targets, where the founder is a director, in the founder sample and find results that are qualitatively similar to those with our main sample.

${ }^{12}$ If a company is a spinoff, then we trace the information back to the founder(s) of its parent company.
} 
relative to the first acquisition announcement day, as in Schwert (1996). We report our results based on the CAR measured from one day prior to one day after the acquisition announcement, but confirm our results with a longer event window of 11 days.

While these short-term measures are relatively insensitive to the benchmark specification (see Brown and Warner, 1985), they could be biased and incomplete if there are systematic differences in how information about acquisition likelihood and terms is revealed to the market before and after the announcement between deals involving targets with a founder CEO versus targets without a founder. Therefore, we also calculate the buy-and-hold abnormal return (BHAR) starting from one day prior to the acquisition announcement to the effective date. Since, at the effective date, all remaining uncertainty surrounding the deal would have been resolved, BHAR does not suffer from the uncertainty bias that CAR potentially does. A downside of long-run measures is that their statistical properties are more susceptible to noise and the choice of an appropriate benchmark. Following the literature, we use the Fama-French-Carhart 4-factor model as our benchmark for the buy-and-hold returns.

\subsection{Sample summary statistics}

All the variables used in this study are listed and defined in the Appendix. Table 1 presents an overview of the number of deals during the sample period. As shown in prior studies, the first three years of the sample (1997-1999) coincide with the large acquisition wave of the late nineties and contain approximately $43 \%$ of the deals. The percentage of targets with a founder CEO ranges from a high of $20.0 \%$ in 2001 to a low of $10.3 \%$ in 2002 , with an average of $16.8 \%$ across the overall sample. Across all sample years, roughly one out of six deals in our sample involves a target where the founder is the CEO.

We also investigate the distribution of the sample across the ten main industry groups as defined in Kahle and Walkling (1996), but do not tabulate this analysis. The largest industry representations for the sample of targets with a founder CEO are Services (26.8\%), Manufacturing (26.1\%), and Financials (23.2\%). While we do not have an a priori reason for removing any of the industries from the sample, we run all our analyses without Financials and, because of its relative dominance in the sample, without 
Services, and find that our results are qualitatively unaffected. Interestingly, for the sample of targets without founder presence, Financials (36.7\%) followed by Manufacturing (30.6\%) and Transportation (11.1\%) have the most dominant industry representations. The differences in year and industry distributions between the sub-samples reinforce the importance of using year and industry fixed effects in our multivariate analysis.

Table 2 presents a summary of, respectively, the return-, target CEO-, firm-, and deal-specific variables we use in the analysis. We present statistics for the whole sample of deals followed by the subsamples of non-founder targets and founder CEO targets. We also report the $p$-values of the differences in the mean and median between the founder CEO group and the non-founder group.

\subsubsection{Return measures}

The average (median) announcement abnormal return for bidders is $-2.20 \%(-1.59 \%)$, which is consistent with results reported in earlier studies involving public targets (see e.g., Moeller et al., 2004). For the sub-sample of deals involving non-founder targets, the average (median) is $-1.97 \%(-1.60 \%)$, whereas for the sub-sample of deals involving founder CEO targets the average (median) bidder gain is $3.36 \%(-1.45 \%)$. Each of these returns is significant at the one-percent level. The difference in average bidder announcement returns between the founder CEO target sub-sample and the non-founder target subsample is $1.39 \%$, which is statistically significant and economically large. Based on the median equity value of bidders in our sample this difference translates into an economically significant value loss of $\$ 81$ million for bidders acquiring a target with a founder CEO.

We next consider the longer run measure of stock performance, BHAR, where we extend our measure of stock performance up to the effective date of the deal. The difference in BHAR between the non-founder targets and the founder CEO targets is $4.13 \%$, which is insignificantly different from zero at conventional levels $(p$-value $=0.205)$. The difference in average synergy returns between deals involving a target with a founder CEO and the sub-sample of non-founder targets is $1.72 \%$ and significant at the onepercent level. The univariate results show preliminary evidence of lower average bidder gains for 
acquisitions of targets with a founder CEO than for targets without a founder. In the remainder of the paper, we focus on multivariate cross-sectional analysis to estimate the correlation between these return measures and firm-level estimates of the human capital of the founder CEO embedded in the value of the target firm.

\subsubsection{CEO, firm, and deal characteristics}

We find no difference in the median age of the CEO based on whether the CEO is the founder or not. The proportion of CEOs close to retirement (CEO age $>60$ ) is $24.6 \%$ for all CEOs in the sample, $23.9 \%$ for CEOs in non-founder targets, and $28.2 \%$ for targets with founder CEOs, but this difference is not statistically significant. However, founder CEOs have a significantly longer tenure than non-founder CEOs and significantly more cash flow and voting rights in their companies than non-founders.

We find a number of significant differences in firm characteristics for both bidders and targets depending on whether the deal involves a target with a founder CEO or without a founder. Target firms in which the CEO is the founder have smaller book value of assets and net sales, a larger ratio of cash to assets, lower leverage, larger ratio of operating income before depreciation to assets, higher sales growth, higher Tobin's Q, more capital expenditures, and lower levels of dividend payments. Targets with founder CEOs are also four times as likely to exhibit a multiple class share structure. We find that, relative to non-founder firms, the equity of targets with founder CEOs has higher idiosyncratic risk, defined as the residual standard deviation from the market model, as well as a higher systematic risk. Consistent with this, we also find a higher fraction of targets belonging to the high-tech industry sectors when a founder CEO is present. ${ }^{13}$

Focusing on the medians, bidders that acquire targets with a founder CEO are also smaller, have a larger ratio of cash to assets, lower leverage, larger ratio of operating income before depreciation to assets, higher Tobin's Q, and higher representation in the high-tech industries than bidders that acquire

\footnotetext{
${ }^{13}$ High-tech companies are identified following a similar definition as in Loughran and Ritter (2004) and Cliff and Denis (2004).
} 
non-founder targets. Finally, there is no difference in the percentage of acquirers that are classified as serial acquirers following the definition in Fuller et al. (2002) across the founder CEO and non-founder samples. ${ }^{14}$ Finally, we observe no significant differences in the means based on whether (a) the deal is a tender offer, (b) the deal is financed via $100 \%$ stock or $100 \%$ cash, (c) the deal is diversifying, or (d) the relative size of the deal. In contrast, deals with non-founder targets are more likely to have competing bidders and the number of days to complete a deal is significantly lower if the target firm has a founder CEO.

\section{Average founder CEO effect on value}

Our main question is whether bidders overpay for targets with a founder CEO, because they overestimate their ability to compensate for any discrete change in the founder's contribution to the target's value after the acquisition and thus, overestimate the target's total value as a stand-alone entity under their control. To answer this question, we first need to establish that the founders contribute to the target value, i.e., whether our sample of takeover targets exhibits an average founder effect similar to that documented in the literature (see e.g., Villalonga and Amit, 2006; Fahlenbrach, 2009; Li and Srinivasan, 2011).

\subsection{Methodology}

Using the same methodology as in the papers cited above, we measure the average founder CEO effect, by estimating the following equation, where value (as measured by Tobin's Q) is the dependent variable:

$$
\mathrm{Q}_{i}=\mathrm{X}_{i} \beta+\text { Founder } \mathrm{CEO}_{i} \gamma+\zeta_{i}
$$

\footnotetext{
${ }^{14}$ See also Aktas et al. (2009) for a discussion of serial acquirers.
} 
where $\mathrm{X}_{i}$ is a matrix of firm- and CEO-specific characteristics, Founder $\mathrm{CEO}_{i}$ is an indicator variable equal to one if the target firm has a founder CEO, and $\zeta_{i}$ is the error term. The coefficient on Founder $\mathrm{CEO}_{i}$ captures the average founder effect across our sample of takeover targets.

We recognize that the relation between value (Tobin's Q) and founder CEO status is potentially endogenous. Therefore, in order to interpret the relation between founder CEO status and value as causal, we follow the existing literature and use an instrumental variables (IV) estimation of average treatments, where we instrument founder CEO presence for the target firm. A good instrument should satisfy the relevance and exclusion conditions, which is typically difficult to accomplish in cross-sectional corporate finance analyses (see e.g., Roberts and Whited, 2013). We rely in our analyses on an instrumental variable for identification even though an instrument is not strictly necessary for identification in this system, due to the non-linearity of the fitted probability in relation to the exogenous variables (e.g., Wooldridge, 2002, p. 621-625). ${ }^{15}$

We follow Fahlenbrach (2009) and use an "Early Incorporation" indicator variable, to denote firms incorporated prior to 1950 , as our instrument. This variable is inspired by the "Dead Founders" variable of Adams et al. (2009) and proxies for whether the founder CEO is dead. This instrument has a strong theoretical and intuitive appeal because dead founders cannot be CEOs and therefore expected to be negatively associated with the presence of a founder CEO. Moreover, Early Incorporation, insofar as it proxies for dead founders, is likely exogenous and unlikely to be caused by performance, which strengthens the case for the argument that it is uncorrelated with performance beyond the control variables in the second-stage regression. Early Incorporation variable satisfies the relevance condition as can be seen in model (2) of Table 3 where the partial correlation between Early Incorporation and founder status, after controlling for all other control variables, is significantly different from zero. The exclusion restriction implies that Early Incorporation should only affect Q through its effect on founder status and thus be uncorrelated with the error term, $\zeta_{i}$, of the second stage regression. While this is not testable,

\footnotetext{
${ }^{15}$ We obtain similar estimates compared to using an instrumental variable when we rely on the non-linearity of the first stage model to achieve identification (unreported).
} 
because $\zeta_{i}$ is unobservable, we find the economic arguments presented above and derived from Adams et al. (2009) and Fahlenbrach (2009) the most convincing. ${ }^{16}$

\subsection{Average founder CEO effect results}

Table 3 presents the results of measuring the average founder effect, where Tobin's Q is the dependent variable. Model (1) is a baseline OLS regression, which ignores the issue of endogeneity. Following Fahlenbrach (2009), we include book value of assets, the number of months the stock is listed on the CRSP database and binary variables for incorporation in Delaware and for when the target is a component of the S\&P 500 Index, and three CEO characteristics: age, length of tenure, and ownership of cash flow rights. We also include year and industry fixed effects, where industries are defined based on the two-digit SIC code main classifications (see Kahle and Walkling, 1996). The coefficient on the Founder CEO indicator is positive and significant, which is consistent with findings in the existing literature.

We next move to the two-stage analysis to account for endogeneity. Specifically, we follow Heckman (1978) and estimate an endogenous binary treatment effects model given that the presence of a founder CEO, which is potentially endogenous, is not a continuous variable. ${ }^{17}$ Model (2) of Table 3 is the first stage probit regression in which the dependent variable is the Founder CEO indicator variable. Following Wooldridge (2002), we add our instrument (Early Incorporation) as a regressor to the first stage model. The coefficient on Early Incorporation is negative and significant, which is consistent with our expectation that for firms incorporated prior to 1950 there is a significantly higher likelihood that the

\footnotetext{
${ }^{16}$ As an alternative instrument, we also considered idiosyncratic risk because the exclusion restriction has been argued in the literature to be justified on economic grounds as well (e.g., Villalonga and Amit, 2006). Q, as a proxy for firm value, should be a function of expected cash flows and expected returns and according to the Capital Asset Pricing Model (CAPM), idiosyncratic risk should have no explanatory power for expected returns. In contrast, founder CEOs, holding undiversified positions in their company, likely care about idiosyncratic risk. However, idiosyncratic risk, particularly in the context of acquisitions and announcement returns, is often seen as a proxy for uncertainty or for more volatile operating decisions, which is likely correlated with expected cash flows, which in turn would affect firm value and, in our opinion, likely violates the exclusion restriction (e.g., Moeller et al., 2007).

${ }^{17}$ For completeness, we also estimate a standard two-stage least squares model (2SLS), which yields results similar to those reported in Table 3. For example, the coefficient on the instrumented Founder CEO variable in the second stage regression following model (5) of Table 3 is $0.938(p$-value $=0.047)$. To conserve space, these regressions are not tabulated.
} 
founder CEO is dead. Model (3) is the second stage regression similar to equation (1), but with the instrumented Founder $\mathrm{CEO}_{i}$ indicator variable as the main regressor. All variables from the first stage, except Early Incorporation, are included in the second stage model. For the treatment effects specification the coefficient on the instrumented Founder CEO continues to be positive and significant with a $p$-value of 0.062 .

In models (4) and (5), we repeat the treatments effect specification and add the variables that Villalonga and Amit (2006) use in their specifications. Specifically, we add leverage, sales growth, the ratio of capital expenditures to plant, property and equipment, the ratio of dividends to the book value of equity, the ratio of R\&D to sales, systematic risk, and whether there is a dual-class share. The coefficient on Early Incorporation remains negative and highly significant in the first stage model. In the second stage model, we continue to find a positive and significant coefficient for the instrumented founder CEO variable. $^{18}$

We confirm the positive effect founder CEOs have on Q using the Abadie-Imbens matching estimator, which does not require an instrumental variable. ${ }^{19}$ We do not tabulate this result, but find that the coefficient on Founder CEO is 0.737 , which is significant at the five-percent level based on using the independent variables from model (1) of Table 3 as the matching covariates. When we include the extended set of control variables used in models (4) and (5), we find that the coefficient is not significant

\footnotetext{
${ }^{18}$ For the OLS specification with the additional control variables, the coefficient on Founder CEO becomes insignificant with a $p$-value of 0.126 (unreported).

${ }^{19}$ The non-parametric matching estimator estimates the effect of a binary treatment (Founder CEO) on the outcome variables (acquirer announcement abnormal returns), where each observation in the sample has an observed treatment assignment and one observable outcome variable depending on whether there is treatment or not. In observational studies with non-randomized treatment, the assumption is that the treatment assignment is independent of the potential outcomes conditional on a set of pre-treatment characteristics, called covariates. For our sample, this method isolates observations with founder CEOs and then, from the sample of non-treated observations, establishes control observations that best "match" the treated ones in multiple dimensions (covariates). The average treatment effect for the treated (ATT) is the difference in bidder announcement abnormal returns received by the treated firms and the control firms. The ATT is bias-corrected and uses heteroskedasticity-consistent standard errors with single matches. The estimator allows control firms to serve as matches more than once, which compared to matching without replacement lowers the estimation bias (but can increase the variance). The ATT estimate is based on one matched control for each treated firm, where "exact" matches are produced on categorical variables, while the matches on continuous variables are based on joint closest matches. The test statistic is adjusted for the fact that continuous variables are not matched exactly. For more detail on this method, see Abadie et al. (2004) and for recent applications in finance, see Almeida et al. (2012) and Bargeron et al. (2013).
} 
at conventional levels. However, the large set of matching covariates results in very poor matches and, as such, is deemed unreliable.

Taken together, we confirm that the average founder CEO effect, documented in the literature, exists for our sample of targets and therefore, the founder CEOs' human capital is embedded in the exante target value. The magnitudes of the coefficients, based on OLS, treatment effects, and the matching estimator are similar to the results reported in the literature for generic samples, and suggest an economically significant founder CEO effect on value for our takeover sample. The next section analyzes the main prediction of the valuable founder hypothesis: A cross-sectional relation between the extent to which the value of the founder CEO's human capital is embedded in the ex-ante target value, and related to the bidder gains and synergy returns.

\section{The valuable founder hypothesis: Firm-level founder CEO effect on value}

We established in Section 3 that our sample of takeover targets exhibits a significant average founder CEO effect, consistent with the results documented in the literature using generic panel data. To further examine whether the bidder overestimates its ability to recreate the value of the founder CEO's human capital embedded in the target firm post acquisition, we first estimate a firm-level measure of the extent to which the founder CEO's human capital (FHC) is embedded in the ex-ante target value. Following this, we present regression analyses using the cross-sectional variation in, respectively, the founder CEO indicator variable, and more importantly, in the firm-specific measure of his human capital (FHC) to explain the cross-sectional variation in bidder gains and synergy returns.

\subsection{Firm-level founder CEO effect on value}

The valuable founder hypothesis relies on measuring the ex-ante value of the founder CEO's human capital for each target firm, and determining whether this firm-specific effect is correlated with bidder gains and synergy returns. Therefore, we want to measure the expected value of a target firm with 
a founder CEO as if the firm did not have a founder. However, in doing so, we have to again consider endogeneity and the potential selection bias introduced by the choice of becoming a non-founder firm.

We follow Campa and Kedia (2002), Lokshin and Sajaia (2004), Fang (2005) and Golubov et al. (2012) in our methodology and use an endogenous switching model which allows for differences in the effect of firm and CEO characteristics on value between targets with a founder CEO and without a founder.

We use Heckman's (1979) two-stage procedure to deal with the issue of selection and endogeneity and start with a first-stage probit model specified as follows:

$$
\begin{aligned}
& \mathrm{NF}_{i}^{*}=\mathrm{Z}_{i} \delta+\varepsilon_{i} \\
& \text { where }\left\{\begin{array}{l}
\mathrm{NF}_{i}=1 \text { if } \mathrm{NF}_{i}^{*}>0 \\
\mathrm{NF}_{i}=0 \text { if } \mathrm{NF}_{i}^{*} \leq 0
\end{array}\right.
\end{aligned}
$$

In equation (2), $\mathrm{NF}_{i}$ is a binary variable equal to one if the target, $i$, does not have a founder (non-founder targets) and zero if the target does have a founder $\mathrm{CEO}$ (founder targets), $\mathrm{NF}_{i}^{*}$ is an unobserved latent variable, $\mathrm{Z}_{i}$ is a matrix that includes both the firm and the CEO characteristics from equation (1) and the instrumental variable, Early Incorporation, described in Section 3.1 that affects the probability of a target firm having a founder $\mathrm{CEO}$, but is uncorrelated with $\mathrm{Q}$, and $\varepsilon_{i}$ is the error term. We also conduct all subsequent analysis with the larger set of control variables, as introduced in models (4) and (5) in Table 3 , and find that our conclusions and results continue to hold. For brevity we do not report these specifications in a separate table.

Next we extend equation (1) to be consistent with equation (2) where $Q_{1, i}$ represents $Q$ for the non-founder cases and $\mathrm{Q}_{2, i}$ represents $\mathrm{Q}$ for the founder cases:

$$
\begin{aligned}
& \mathrm{Q}_{1, i}=\mathrm{X}_{i} \beta_{1}+\zeta_{1, i} \\
& \mathrm{Q}_{2, i}=\mathrm{X}_{i} \beta_{2}+\zeta_{2, i} \\
& \text { and }\left\{\begin{array}{l}
\mathrm{Q}_{i}=\mathrm{Q}_{1, i} \text { iff } \mathrm{NF}_{i}=1 \\
\mathrm{Q}_{i}=\mathrm{Q}_{2, i} \text { iff } \mathrm{NF}_{i}=0
\end{array}\right.
\end{aligned}
$$


We only observe either $\mathrm{Q}_{1, i}$ or $\mathrm{Q}_{2, i}$, depending on whether we have a non-founder target or a founder target, respectively. The error terms of the continuous equations (3), $\zeta_{i}$, and those of the selection model (2), $\varepsilon_{i}$, are allowed to be correlated to model the endogeneity. This yields the following nondiagonal covariance matrix $\Omega$ for $\zeta_{1, i}, \zeta_{2, i}$, and $\varepsilon_{i}$ :

$$
\Omega=\left[\begin{array}{ccc}
\sigma_{11} & \sigma_{12} & \sigma_{1 \varepsilon} \\
\sigma_{12} & \sigma_{22} & \sigma_{2 \varepsilon} \\
\sigma_{1 \varepsilon} & \sigma_{2 \varepsilon} & 1
\end{array}\right]
$$

To estimate the model, we have:

$$
\begin{aligned}
\mathrm{E}\left[Q_{1, i}\right] & =\mathrm{E}\left[Q_{i} \mid \mathrm{NF}_{i}=1\right]=\mathrm{E}\left[Q_{i} \mid \mathrm{NF}_{i}^{*}>0\right] \\
& =\mathrm{E}\left[\mathrm{X}_{i} \beta_{1}+\zeta_{1, i} \mid \mathrm{Z}_{i} \delta+\varepsilon_{i}>0\right]=\mathrm{X}_{i} \beta_{1}+\mathrm{E}\left[\zeta_{1, i} \mid \varepsilon_{i}>-\mathrm{Z}_{i} \delta\right]
\end{aligned}
$$

OLS will result in inconsistent estimates because the conditional expectation $\mathrm{E}\left[\zeta_{1, i} \mid \varepsilon_{i}>-\mathrm{Z}_{i} \delta\right]$ has a non-zero mean given the correlation between $\varepsilon_{i}$ and $\zeta_{1, i}$. However, under the assumption of joint-normality of the two error terms $\varepsilon_{i}$ and $\zeta_{1, i}$ from equations (2) and (3) we have $\mathrm{E}\left[\zeta_{1, i} \mid \mathrm{NF}_{i}^{*}>0\right]=\operatorname{cov}\left(\zeta_{1, i}, \varepsilon_{i}\right) \times$ $\operatorname{imr}_{1}\left(\mathrm{Z}_{i} \delta\right)$, where $\mathrm{imr}_{1}\left(\mathrm{Z}_{i} \delta\right)=\varphi\left(\mathrm{Z}_{i} \delta\right) / \Phi\left(\mathrm{Z}_{i} \delta\right)$, defined as the inverse Mills ratio. The functions $\varphi(\cdot)$ and $\Phi(\cdot)$ represent, respectively, the density and cumulative distribution functions of the standard normal. In other words, if we augment equation (5) with the inverse Mills ratio to proxy for the non-zero conditional mean, the residual of this augmented specification will have a zero mean and can thus be consistently estimated using OLS. Consequently, to estimate Q for founder targets we have:

$$
\mathrm{E}\left[\zeta_{2, i} \mid \mathrm{NF}_{i}^{*} \leq 0\right]=\operatorname{cov}\left(\zeta_{2, i}, \varepsilon_{i}\right) \times \mathrm{imr}_{2}\left(\mathrm{Z}_{i} \delta\right)
$$

The inverse Mills ratio, $\operatorname{imr}_{2}\left(Z_{i} \delta\right)$, in equation (6) is equal to $\left[-\varphi\left(Z_{i} \delta\right) /\left(1-\Phi\left(-Z_{i} \delta\right)\right)\right]$. Next we define the hypothetical value of Q for a founder target as the value that Q would have been if the target had been a non-founder target instead: ${ }^{20}$

\footnotetext{
${ }^{20}$ We acknowledge that the estimation of $\mathrm{Q}$ for founder firms should not be prone to a selection bias, since a nonfounder firm is unlikely to switch and become a founder firm. In untabulated analyses, we estimate the hypothetical value of $\mathrm{Q}$ for founder firms by setting the inverse Mills ratio equal to zero. Our results remain the same using asymmetric or one-way switching.
} 


$$
\mathrm{Q}_{2, i}^{\text {Hypothetical }}=\mathrm{E}\left[\mathrm{Q}_{1, i} \mid \mathrm{NF}_{i}^{*} \leq 0\right]=\mathrm{X}_{i} \beta_{1}+\operatorname{cov}\left(\zeta_{1, i}, \varepsilon_{i}\right) \times \mathrm{imr}_{2}\left(\mathrm{Z}_{i} \delta\right)
$$

Finally, the estimated impact of the founder CEO on the target value, or the value of the founder CEO's human capital (FHC) is defined as the difference between the actual value of $\mathrm{Q}$ for a target with a founder CEO and its hypothetical value:

$$
\mathrm{FHC}_{i}=\mathrm{Q}_{2, i}^{\text {Actual }}-\mathrm{Q}_{2, i}^{\text {Hypothetical }}
$$

In equation (8), $\mathrm{FHC}_{i}$ represents the value of the founder CEO's human capital measured for each firm and is the main variable for testing the valuable founder hypothesis.

Recall that the valuable founder hypothesis predicts that the market's skepticism regarding overpayment in an acquisition comes from the bidder's overestimation of the target's stand-alone value under the bidder's control by overestimating its ability to, fully or partially, substitute the diminished founder CEO's human capital post acquisition. FHC is our proxy for this specialized resource and is expected to exhibit a discrete change after the acquisition. To the extent that FHC measures this specialized resource and therefore proxies for overpayment by the bidder, we expect a negative correlation between FHC and bidder abnormal returns.

\subsection{Univariate results: Founder CEO human capital (FHC)}

We next present the univariate results from estimating the firm-level values of the founder CEO's human capital (FHC) using equations (2) through (8) from Section 4.1. Note that equation (2) is the firststage probit model from the previous section and is reported as model (2) in Table $3 .{ }^{21}$ To estimate the hypothetical value of Q for founder targets, as summarized in equation (7) above, we rely on the subsample of non-founder targets and use the following estimates based on the switching model:

\footnotetext{
${ }^{21}$ Note that the dependent variable in model (2) of Table 3 equals one for founder CEO targets and zero otherwise, while the dependent variable in equation (2) equals one for non-founder targets and zero otherwise.
} 


$$
\begin{aligned}
\mathrm{Q}_{2, i}^{\text {Hypothetical }}= & 3.806^{a}-0.010 \times \text { CEO age }-0.026 \times \ln (1+\text { CEO tenure })-1.744^{c} \\
& \times \text { CEO CF right }-0.09^{b} \times \ln \left(\text { Target }^{\prime} \text { s total assets }\right)-0.183^{a} \\
& \times \ln (1+\text { Months on CRSP })+0.055 \times \text { Delaware }+0.497^{a} \times S \& P 500-0.119 \\
& \times \operatorname{imr}_{1}\left(\mathrm{Z}_{i} \delta\right), \text { with Observations }=702 \text { and Adjusted } R^{2}=10.5 \%
\end{aligned}
$$

The variable $\operatorname{imr}_{1}\left(\mathrm{Z}_{i} \delta\right)$ is the inverse Mills ratio defined in the previous section (all other variables are defined in the Appendix). The superscripts ${ }^{\mathrm{a}},{ }^{\mathrm{b}}$, and ${ }^{\mathrm{c}}$ denote significance at the $1 \%, 5 \%$, and $10 \%$-level, respectively. While we do not need the regression for the sample of founder CEO firms, we stress the importance of allowing for differences in the effect of firm and CEO characteristics on value between targets with a founder CEO and targets without a founder in the endogenous switching model. For example, the coefficients on size, CEO's cash flow right, months on CRSP, and inclusion in the S\&P500 are all significant for the sub-sample of non-founder targets, but not for the founder CEO targets. This is consistent with the idea that incentives are likely organized differently between founder CEO firms and non-founder firms. ${ }^{22}$

Table 4 presents summary statistics for FHC. The mean value for FHC is 0.854 , which is significantly larger than zero with a $p$-value of 0.014 . The median FHC is 0.159 and significant at the one-percent level and also economically large as it represents $10.8 \%$ of the median Q of the targets. Note that for 39 percent of the targets with a founder CEO the value of FHC is negative, which suggests these firms would have had a higher value (Q) if they had been non-founder instead of with a founder CEO. In unreported analysis we find that negative values for FHC do not drive our findings.

\subsection{Cross-sectional analysis of the founder CEO's human capital: Bidder gains}

\footnotetext{
22 The switching model allows for important heterogeneity which yields specific projections determined by the switch between targets with a founder CEO and without a founder. This alleviates the concern that the relation between the firm-specific value of the founder CEO's human capital and bidder gains is driven by a poor fit of the model because of some unidentified non-linear relationship between firm characteristics and firm value. Moreover, when we estimate the switching model with the additional control variables used in Villalonga and Amit (2006), described in Section 3.2, the adjusted R-squared increases to $13.7 \%$ and our main conclusions continue to hold.
} 
We next use cross-sectional regression analysis to test the main prediction of the valuable founder hypothesis: insofar as the FHC estimate proxies for the founder CEO's human capital embedded in the target value, FHC is expected to be negatively associated with bidder gains and synergy returns.

In our first set of regression specifications, we focus on bidder gains as the dependent variable, measured as the three-day market model-adjusted cumulative abnormal return for the bidder. We specify variations on the following OLS model, where we include either the Founder CEO variable, the firm-level measure of the Founder CEO's human capital, FHC, or both as a regressor:

$$
\mathrm{CAR}_{i}=\mathrm{W}_{i} \theta+\text { Founder } \mathrm{CEO}_{i} \psi+\mathrm{FHC}_{i} \lambda+\tau_{i}
$$

Each regression uses the same matrix of bidder and deal control variables, $\mathrm{W}_{i}$, based on the existing literature (see e.g., Moeller et al., 2004; Bargeron et al., 2008). Each regression includes the target firm's CEO's age and cash flow rights and an indicator variable which denotes whether the target firm has a multiple-class share structure. In addition, the following bidder and deal characteristics are included: bidder size, cash-to-assets ratio, debt-to-assets ratio, Tobin's Q, relative size, and indicator values for whether the deal is a tender offer, an all-equity deal, an all-cash deal, a diversifying deal, or a competed deal. Note that the differences in bidder size, target size, performance of the target, and the number of competed deals as reported in Table 2, if anything, would suggest better bidder returns for the founder CEO sub-sample. ${ }^{23}$ Finally, each regression model includes year and industry fixed effects.

We report the results in Table 5. In model (1), we include the binary founder CEO variable, which represents the average founder CEO effect across the full sample. The coefficient on Founder CEO is negative and significant at the ten-percent level. The results in model (1) implies that, all else equal, bidder gains are 1.2 percentage points lower if the target firm has a founder CEO compared to when it

\footnotetext{
${ }^{23}$ We recognize that our measure for competition ignores the type of pre-announcement competition as defined in Boone and Mulherin $(2007,2008)$; however, they find no statistical differences in bidder returns on the basis of auctions versus negotiations. Also, there is no a priori reason to assume that price pressure issues related to equity financing play a more important role between the two sub-samples (e.g., Mitchell et al., 2004).
} 
does not have a founder. However, there are two issues with this specification. First, the founder CEO indicator variable does not take into account the concerns associated with selection and endogeneity. Therefore, in model (2) we use the instrumented version of the founder CEO variable, similar to the analysis in Table 3. While the coefficient retains a negative sign, it is no longer significant. Therefore, based on the average founder CEO effect we do not find evidence of a negative association with bidder gains.

A second, and more important, issue is that the coefficient on the founder CEO indicator represents the marginal correlation between the average, instead of a firm-level, measure of human capital and announcement abnormal returns. As noted in the previous section, there is a wide dispersion in the founder CEO effect at the firm level. To better exploit this cross-sectional variation, we replace the binary founder CEO variable with our firm-level measure of the founder CEO's human capital (FHC) in model (3). The coefficient on FHC is negative and highly significant ( $p$-value $<0.001$ ), suggesting that higher levels of FHC are associated with lower bidder gains, which is consistent with the predictions of the valuable founder hypothesis. The effect is also economically large: A one standard deviation increase in FHC results in a drop of 1.6 percentage points in bidder gains and a change from the $25^{\text {th }}$ to the $75^{\text {th }}$ percentile results in half a percentage point lower bidder gains.

In model (4), we include both the instrumented binary founder CEO variable and the firm-level measure of founder human capital. The coefficient on FHC remains negative and highly significant, while the coefficient on the average founder effect remains insignificant. When we run the same specification (unreported) with the binary founder CEO variable that is not instrumented, we find a similar coefficient and significance for FHC. The coefficient on the average founder effect in this regression is also insignificant. In model (5), we add the target's Tobin's Q net of FHC, which reflects the portion of Q which is unexplained by the founder CEO presence. The coefficient on FHC continues to be negative and significant at the one-percent level, while Tobin's Q net of FHC has no association with bidder gains.

The results so far are consistent with the valuable founder hypothesis; larger values of FHC embedded in the target value and expected to diminish after the deal are associated with lower bidder 
gains. Note that FHC can only be estimated for targets with a founder CEO and, therefore, in the regressions discussed above, we substitute a value of zero for FHC whenever the deal involves a nonfounder target. Therefore, we investigate whether the coefficients on FHC in the regression specifications of models (1) through (5) are significant because of this substitution and estimate the regressions using only the sub-sample of targets with a founder CEO. We begin with model (6) which shows the regression results solely on the basis of the control variables. In model (7) we add FHC, and in model (8) we also add Tobin's Q of the target net of FHC as regressors. The coefficient on FHC continues to be negative and significant at the one percent level within the founder CEO sample. Note also that the adjusted Rsquared improves from $7.2 \% \%$ to $13.0 \%$ when FHC is added in model (7) relative to model (6). This suggests that an economically large fraction of the total variation in bidder gains for deals that involve targets with a founder CEO is explained by the variation in our measure of the value of the founder CEO's human capital (FHC).

We verify the robustness of the coefficients on FHC and estimate each regression from Table 5 with the additional target firm control variables used by Fahlenbrach (2009) to estimate the founder CEO effect: indicator variables for Delaware incorporation and S\&P 500 inclusion, and the natural logarithm of, respectively, the number of months since incorporation and the number of years the CEO has been in her position. We then rerun each regression again and also add the control variables used in Amit and Villalonga (2006) in their estimation of the founder CEO effect, which include the ratio of dividends to the book value of equity, leverage, systematic risk, the ratio of $R \& D$ to sales, the ratio of capital expenditures to plant, property and equipment, and sales growth. All variables are further defined in the Appendix. While we do not tabulate the results, the coefficient on FHC continues to be significant at the one-percent level or better in each of the alternative specifications. ${ }^{24}$

\footnotetext{
${ }^{24}$ We run this additional specification with and without the extra control variables added to the switching model in order to estimate FHC. The coefficient on FHC remains significant at the one-percent-level in each of these alternative specifications. The results of this analysis are available upon request.
} 


\subsection{CEO departures and the valuable founder hypothesis}

A potential implication of the valuable founder hypothesis is that the relation between FHC and bidder gains is more pronounced for cases where the founder CEO departs after the deal relative to cases where he is retained by the bidder. When the founder CEO departs, the entire value of his human capital is lost after the acquisition. In contrast, the founder CEO's human capital may only be partially lost after the acquisition if he were to be retained by the bidder. Furthermore, Wulf and Singh (2011) and Bargeron et al. (2013) show that CEO retention after an acquisition is positively associated with the target firm's performance. Their findings imply that (1) the founder CEO target's value may be lower for deals in which the founder CEO departs post-acquisition and, consequently, (2) while only a fraction of his human capital may be lost when the target's founder CEO remains employed by the acquirer, this may be a fraction of a larger value of FHC. Alternatively, CEO departure versus retention may not matter if the market perceives the influence that the founder CEO can exert after the acquisition to be drastically diminished and statistically indistinguishable from cases where the CEO departs. The impact of CEO departures on the relation between FHC and bidder gains is, therefore, an empirical issue.

We define CEO departure as follows. For each founder CEO firm in our sample we conduct a web-based search for evidence that the CEO either departs or remains with the merged company during the five year period following the effective date of the deal. Ideally, we want to distinguish cases where the founder CEO remains with the merged company because of his perceived value in the long-run versus cases where he stays for a relatively short period potentially to facilitate the transition and integration of the two merging entities. While selecting a cutoff to determine what is considered CEO departure versus CEO retention is by definition arbitrary, we follow Martin and McConnell (1991) and Kini, Kracaw, and Mian (2004) and define cases where the CEO departs within two years after the completion of the deal as 
CEO departure (CEO Departure $=1)$ and cases where the CEO is still employed by the merged entity after two years as CEO retention (CEO Departure $=0){ }^{25,26}$

For the142 founder CEOs in our sample, 101 (71.1\%) founder CEOs depart within two years after the completion of the deal. Of the 41 CEOs that remain with the bidder for two years or longer, only four have an executive position (CEO or COO). The most common position or title is Director or Vice President, suggesting a reduced role despite being retained by the bidder.

Consistent with the idea that an acquirer may want to retain the most valuable CEOs, we find that the median FHC for retained CEOs is 0.416 compared to 0.118 for CEOs that depart within two years (unreported). The difference is marginally significant $(p$-value $=0.096)$. In model (9) of Table 5 , we replicate model (8), but condition FHC on whether the founder CEO departs (FHC | CEO Departure = 1) or stays with the acquirer for at least two years $(\mathrm{FHC} \mid \mathrm{CEO}$ Departure $=0)$. Consistent with the idea that more of the ex-ante value contributed by the founder CEO is lost after the deal when the CEO is not retained by the acquirer, we find that the coefficient is negative and significant when we condition on founder CEOs who depart within two years. In contrast, for founder CEOs who remain with the bidder for two or more years, there is no significant relation between FHC and bidder gains. The interaction term between FHC and CEO Departure (unreported) has a negative sign, but with a $p$-value of 0.129 falls just outside of commonly accepted significance levels. In unreported analysis, we find a similar result when we estimate the regression for the sample split into deals with and without CEO departure. The relation between FHC and bidder gains is negative and significant only for the sub-sample where the founder CEO departs within two years.

\footnotetext{
${ }^{25}$ We also considered the methodology as in Bargeron et al. (2013) and use the information in the merger document to determine whether the CEO departs or is retained by the acquirer. However, the information in the merger document is often ambiguous with respect to this determination. In many cases there is no specific mention about whether the CEO would be retained by the acquirer. There is usually, however, a generic statement indicating that the officers of the target company will or will not be officers in the new company. The length of time a CEO is expected to stay is also often unclear from the merger document.

${ }^{26}$ In a recent paper, Cain, Denis, and Denis (2011) analyze earnout contracts offered to target CEOs by the bidder for purposes of retention. They find that the median earnout period is also approximately two years. Earnout contracts are most commonly used for non-public targets and are therefore generally not available for our sample of public targets.
} 
While these results are consistent with the valuable founder hypothesis, we want to express caution when interpreting them. Splitting the founder CEO sample based on CEO retention yields relatively small sub-samples. Moreover, when we consider CEO departure versus CEO retention based on information available exclusively in the merger document, the coefficient for the sub-sample of departing founder CEOs is statistically indistinguishable from zero. Interestingly, 37 of the 71 founder CEOs who, according to the merger document, were supposed to remain with the bidder depart within two years after the deal becomes effective, making the merger document-based definition of departure less informative.

\subsection{Returns to completion and synergy returns}

We next consider the possibility that systematic differences in the takeover process between bidders acquiring founder CEO targets and bidders acquiring non-founder targets during the period starting with the time of announcement until the time of completion may affect our results. In Table 6 , we repeat the models from Table 5 where we use the Fama-French-Carhart 4-factor model-adjusted buy-andhold returns (BHAR) instead of the short-term announcement return (CAR) as the dependent variable. In model (1), we find that the non-instrumented binary founder CEO variable is not significant and the coefficient on the instrumented founder CEO variable is also insignificant and switches to a positive sign in model (2). The coefficients on FHC, however, continue to be significantly negative at the one-percent level or better in each of the subsequent specifications. Economically the relation between FHC and BHAR is also large with an increase in FHC from the $25^{\text {th }}$ to the $75^{\text {th }}$ percentile associated with a drop of $3.1 \%$ in bidder abnormal returns from the announcement to the completion of the deal.

The valuable founder hypothesis also makes predictions for synergy returns. The total synergy could be viewed as the difference between the operating synergy, obtained by merging the bidder and the target, and the value loss in the stand-alone value of the target, arising from the loss of a specialized resource in the target, i.e., the founder CEO's human capital.

In Table 7 we focus on synergy returns as the dependent variable and include both bidder and target control variables. Under the valuable founder hypothesis we expect a negative association between 
synergy returns and the founder CEO indicator variable and, in particular, with FHC. In models (1) and (2) of Table 7, we find that the coefficient on the founder CEO indicator variable is indeed negative, but not significant regardless of whether we instrument the variable or not. In each of the subsequent regression models in Table 7, where we include the firm-specific measure of the founder CEO's human capital, FHC, either in place of, or alongside the founder CEO indicator variable, we find that the coefficient on FHC is consistently negative and significant at the one-percent level, irrespective of whether we use the full sample or the founder CEO sub-sample alone. We note that in model (5), while the coefficient on FHC continues to be negative and significant at the one-percent level, Tobin's Q net of FHC has a positive association with synergy gains. The role of Tobin's Q in explaining synergy returns does, therefore, rely substantially on whether Q is explained through the presence of the founder CEO (FHC) or not (Tobin's Q net of FHC). Furthermore, in unreported regressions, we find the association between FHC and both bidder gains and synergy returns to be significantly negative particularly for the subset of CEOs who depart within two years after the merger is completed. Finally, whether we instrument the founder CEO indicator variable or not does not influence the coefficients we estimate for FHC in Tables 5 through 7.

In summary, our evidence suggests that the market perceives bidders as overpaying for the value of the founder CEO's human capital embedded in the target firm because they overestimate their ability to retain this value under their control. Taken together, these results support the valuable founder hypothesis.

\section{Alternative explanations and robustness}

\subsection{Are bidder returns lower because target founders bargain for higher premiums?}

An alternative explanation for finding lower bidder gains when the target CEO is a founder, or for higher values of his human capital (FHC), is that target founders may exert more control over the deal and are better bargainers on behalf of their shareholders. This could potentially result in higher premiums and a bigger portion of the total takeover gains going to the target shareholders, leaving less for the bidder 
shareholders. ${ }^{27}$ A bargaining explanation predicts that target premiums, and more importantly, target relative gains should be positively correlated with the presence of a founder CEO and the value of his human capital. In the context of a bargaining argument, it is important to note that the valuable founder hypothesis makes no predictions with respect to target premiums. The overpayment implied in the valuable founder hypothesis is not a transfer of wealth that can be measured using the target premium, as the founder's human capital is embedded in the target's price. ${ }^{28}$

In models (1) through (4) of Table 8, we present the results for the regression analysis using target premiums as the dependent variable. Target premiums are measured as the three-day market modeladjusted cumulative abnormal returns. As before, model (1) includes the binary Founder CEO variable. The coefficient is 0.0056 and is statistically indistinguishable from zero ( $p$-value $=0.801$ ), suggesting there is no difference in the target premium between founder CEO targets and non-founder targets. Model (2) shows that we obtain a similar result when we use the instrumented version of the Founder CEO variable. This result is consistent with the premise of the valuable founder hypothesis that the wealth transfer from bidder shareholders to target shareholders is already reflected in the target price prior to the bid, but is inconsistent with the bargaining explanation. In model (3), we add FHC and the target's Tobin's Q net of FHC to the specification. Inconsistent with the bargaining explanation, we find that FHC has a negative and significant coefficient ( $p$-value $=0.028$ ). Finally, when we focus on the founder CEO sub-sample exclusively, we find that the coefficient on FHC in model (4) is negative, but statistically

\footnotetext{
${ }^{27}$ Note that founder CEOs may also be bargaining more on their personal behalf, in which case there would be no relation between founder presence and target premiums. However, we have no a priori reason to believe that agency conflicts are more severe for founder CEOs, and even if they were, this would not offer an alternative to our valuable founder hypothesis as bargaining on the CEO's personal behalf would be at the expense of the target shareholders and, thus, would not explain the negative relation between FHC and bidder gains which we find.

${ }^{28}$ For example, if the current price of the target under the control of the founder CEO is $\$ 100$ where $\$ 10$ is attributed to the value of the founder CEO's human capital, the bidder would have to pay at least $\$ 100$ in order for the target to accept the bid. If we further assume that the value of the synergy, $S$, is estimated, with or without hubris, independent of whether the target has a founder CEO, then from the market's perspective, the target under control of the bidder is valued at $[S+p \times \$ 90+(1-p) \times \$ 100]<[S+\$ 100]$ if $p>0$, where $p$ is the probability that the $\$ 10$ founder value is lost after a control change. In other words, making a bid for $[S+\$ 100]$ would have a negative effect on bidder gains because $p \times \$ 10>0$, but does not necessarily affect the target premium. Note also that the valuable founder hypothesis does not predict that the bidder pays too much for the acquisition in total per se, as long as $p \times$ $\$ 10-S<0$. The valuable founder hypothesis however, isolates one component of overpayment, as identified by a specific value resource in the target, i.e. the ex-ante value of the target that is attributed to the founder CEO.
} 
indistinguishable from zero ( $p$-value=0.207). We also run models (3) and (4) without the target's Tobin's Q net of FHC (not reported) and confirm that FHC yields similar coefficients and significance levels as reported in models (3) and (4).

Betton et al. (2008) show that bidder gains are a function of both target run-up and premium and, premiums do not reflect firm size. Consequently, premiums are often difficult to interpret unambiguously as a measure of bargaining. To determine a better proxy for bargaining power, we first address the size issue and follow Malatesta (1983) who argues that takeover gains are typically better estimated using dollar-denominated abnormal wealth gains to reflect the difference in size between bidders and targets. Following Bradley et al. (1988) and Kale et al. (2003), we use dollar-denominated wealth gains for the target, as follows: $\mathrm{TWLTH}_{i}=\mathrm{TMV}_{i} \times \mathrm{TCAR}_{i}$. Similarly, the bidder wealth gain is defined as $\mathrm{BWLTH}_{i}=$ $\mathrm{BMV}_{i} \times \mathrm{BCAR}_{i}$, where $\mathrm{TMV}_{i}\left(\mathrm{BMV}_{i}\right)$ is the market value of equity of the target (bidder) measured 22 trading days prior to the announcement of the acquisition and $\operatorname{TCAR}_{i}\left(\mathrm{BCAR}_{i}\right)$ is the 3-day cumulative abnormal return around the deal's announcement for the target (bidder). The relative target gain, TPROP is defined as in Kale et al. (2003). TPROP is the target's proportion of the total acquisition synergy defined as $\mathrm{TWLTH}_{i} / \mathrm{SYNERGY}_{i}$ if SYNERGY $>0$ and $\left(1-\mathrm{TWLTH}_{i} / \mathrm{SYNERGY}_{i}\right)$ if $\mathrm{SYNERGY}_{i}<0$, where $\mathrm{SYNERGY}_{i}=\mathrm{TWLTH}_{i}+\mathrm{BWLTH}_{i}$.

In models (5) through (8) of Table 8, we repeat models (1) to (4) and replace the dependent variable with TPROP. From these regression models we confirm that neither Founder CEO nor FHC has a significantly positive coefficient, providing no support for the bargaining explanation. ${ }^{29}$ Replacing target abnormal returns with target Fama-French-Carhart 4-factor model-adjusted buy-and-hold abnormal returns from one day before the announcement until the effective date (untabulated) provides the same conclusions.

\footnotetext{
${ }^{29}$ Alternatively, we measure relative wealth gains as in Ahern (2012) where we subtract the bidder's wealth gain from the target's wealth gain, and divide the difference by the market value of equity of the combined firms measured as of 22 trading days prior to the announcement of the acquisition. The results of models (5) through (8) of Table 8 are similar when we use this alternative definition (unreported).
} 


\subsection{Performance leading up to the acquisition}

The valuable founder hypothesis relies on the founder CEO being a valuable resource for the target prior to the acquisition. Adams et al. (2009) show that founder CEOs are more likely to exit their role, and thus cede control to outsiders when performance is high. In contrast, Klasa (2009) shows that controlling families of publicly traded firms do not time the market when selling their controlling stakes to bidders that either buy the whole firm or buy the family's controlling stake. We investigate this issue for our sample because if ex-ante performance improves more for founder CEO targets than for other targets, this may bias our result towards finding evidence for the valuable founder hypothesis.

In unreported analysis, however, we find that the median Tobin's Q drops for target firms with a founder $\mathrm{CEO}$, while it increases for non-founder targets during the year prior to the acquisition. The difference in the median change in Tobin's Q between founder CEO targets and non-founder targets is significant and suggests that the founder CEO's value to the target is declining in the run-up to the acquisition. ${ }^{30}$ Moreover, if founder CEO's are more likely to cede control to outsiders when performance is high, we would expect to see a more negative relation between the change in Q and CEO retention for the subsample of founder CEO targets than for the subsample of non-founder targets. We find no support for this in our sample (unreported).

Finally, in Table 9 we revisit model (8) of Table 5 (and similarly for Tables 6 and 7, unreported) and estimate a number of alternative regression specifications. In model (1), we add the percentage change in Q over the year prior to the acquisition as a regressor. In model (2), we include the one-year lagged estimate of FHC. Lagged Q estimates of FHC are noisier resulting in lower significance levels, but overall, our results remain qualitatively similar. In model (3), we interact FHC with an indicator variable equal to one if the target initiated the deal and zero otherwise. Data on whether the bidder or target

\footnotetext{
${ }^{30}$ Note that while founder value may be declining prior to the acquisition, we find that the founder CEO's presence remains significantly associated with the target Q. In fact, the perception that the founder value is declining for the targets may actually feed acquirer hubris as they may think that the founder resource is not as valuable as it may have been earlier. However, our empirical evidence suggests that such a belief, if it exists, would be false.
} 
initiated the deal is collected from the merger documents for the sample of founder CEO targets. In 23 cases we are unable to determine unambiguously who initiated the deal and we exclude these from the sample for this regression. Insofar as our results are being driven by the timing of the target CEO to cede control at the peak of their performance, we would expect our relation between FHC and bidder CAR to be weaker for bidder initiated deals and more pronounced for target initiated deals. Model (3) shows, however, that there is no significant difference in the relation for target versus bidder-initiated deals. Also, the coefficient on FHC shows that, for bidder initiated deals, the relation between FHC and bidder CAR continues to be negative and significant.

In summary, our results do not appear to be driven by mean reversion where founder CEOs time their decision to cede control to outsiders on the basis of their performance.

\subsection{Alternative regression specifications}

From Table 4 we know the distribution of FHC is positively skewed. To better understand the effect of the distributional properties, we estimate non-parametric median regressions based on the specifications of models (3), (5), and (8) from Tables 5, 6, and 7 using respectively Bidder CAR $(-1,+1)$, Bidder BHAR $(-1,+1)$, and Synergy CAR $(-1,+1)$ as the dependent variables. In each of these models, reported in Table 10, the coefficients on FHC remain negative and statistically significant with coefficients similar to those obtained from our OLS regressions.

In unreported analysis we estimate a number of alternative regression specifications, based on the findings in the literature. For example, Villalonga and Amit (2006) find that the founder effect in their analysis is particularly strong for founders who have a sufficient amount of control to be influential, but not so much that they become entrenched. Given the relatively high levels of cash flow rights associated with founder CEOs, we run all our tests with an additional binary regressor set equal to one if the target CEO has more than $50 \%$ of the cash flow rights. While we typically find that the coefficient on this variable is insignificant, the coefficient on FHC continues to be negative and significant when we consider bidder gains and synergy returns. 
We also consider the possibility that bidder returns may be a function of deal anticipation (Song and Walkling, 1993; Cai et al., 2011), the difficulty of valuing a target firm (Officer et al., 2009), or whether a bidder is classified as a serial acquirer (Fuller et al., 2002; Aktas et al., 2009, 2012). Specifically, we add the following variables for the target firm; operating performance (operating income before depreciation to total assets), CEO tenure, an indicator variable for high-tech industry, and idiosyncratic risk. We also add an indicator variable for whether a bidder is a serial acquirer ${ }^{31}$ and the bidder's run-up period buy-and-hold abnormal returns (for the period of 63 trading days to six trading days prior to the announcement). In addition, we rerun our analysis after dropping clustered deals from the sample, defined as deals by the same bidder announced within three days of each other (10 observations). Moeller et al. (2005) identify 1998-2001 as a period in which a disproportionate number of "large loss" deals occurred. We also rerun our analysis including an indicator variable for this period instead of using year indicator variables. None of these alternative specifications changes the general findings of the paper. The coefficients on FHC consistently remain statistically significant with bidder gains and synergy returns as the dependent variables. For none of these alternative specifications do we find a positive association between either target premiums or target relative gains with either the Founder CEO variable or FHC.

\section{Conclusion}

The literature on mergers and acquisitions, starting with Roll (1986), has often addressed the issue of managerial hubris leading to overpayment in acquisitions. For example, the observation of economically significant negative bidder returns for some public bidder acquisitions is frequently

\footnotetext{
${ }^{31}$ Fuller et al. (2002) find that serial acquirers are associated generally with lower bidder returns. We flag each deal in our sample if it fits the definition of a serial acquirer as in Fuller et al. (2002) except that we consider the threeyear period prior to the announcement of the deal in our sample, as opposed to any three-year window, to check whether five or more deals, using their selection criteria, have been announced. For the founder CEO target subsample, $26.8 \%$ of the bidders meet the criteria to be classified as serial acquirers, as also $28.9 \%$ of the bidders for the non-founder target sub-sample. We rerun our tests without serial acquirers and, separately, with an indicator variable for serial acquirers, to see if this classification biases our results.
} 
attributed to managerial overconfidence, arrogance, or honest misjudgment of value. We argue, however, that positive bidder gains are not necessarily inconsistent with overpayment, nor are negative bidder gains always a direct consequence of overpayment. Insofar as managerial hubris leads to overpayment in acquisitions, it is important to note that this overconfidence derives from two non-mutually exclusive sources: (i) the target's stand-alone value under the bidder's control is overestimated, or (ii) synergies from the combined entity are overestimated. To the best of our knowledge, this is the first paper that tries to disentangle these two factors, while not relying on proxies for overconfidence or focusing exclusively on average bidder gains as evidence of managerial hubris. In this paper, we provide a unique test of the first source of overpayment by isolating a part of the target's ex-ante value that is attributable to a founder CEO and is expected to decline after consummation of the deal, and relating this to bidder gains and synergy returns.

We show that target firms exhibit a significant founder effect similar to that shown in the literature for generic firms analyzed with panel data. Using an endogenous switching model, we show that firm-level measures of the founder effect, which we interpreted as the value of the founder CEO's human capital, exhibit a strong negative correlation with bidder gains and synergy returns. Our method allows us to separate high target values per se from targets whose high values are explicitly due to the presence of a founder CEO. Our evidence is consistent with bidders overestimating their ability to recreate the value of this specialized resource in the target firm, which is likely to undergo a significant decline after the acquisition, and consequently overestimating the value of the target as a stand-alone firm under their control. The negative relation between bidder gains and FHC persists when the founder CEO departs the acquirer within two years after the completion of the takeover, but not when the CEO is retained for two years or more. Finally, we find no evidence suggesting that founder CEOs have more bargaining power and appropriate a larger share of the total gains on behalf of their shareholders. 


\section{References}

Abadie, Alberto, and Guido Imbens, 2006, Large sample properties of matching estimators for average treatment effects, Econometrica 74, 235-267.

Abadie, Alberto, David Drukker, Jane Leber Herr, and Guido Imbens, 2004, Implementing matching estimators for average treatment effects in Stata, Stata Journal 4, 290-311.

Adams, Renée, Heitor Almeida, and Daniel Ferreira, 2009, Understanding the relationship between founder-CEOs and firm performance, Journal of Empirical Finance 16, 136-150.

Aktas, Nihat, Eric de Bodt, and Richard Roll, 2009, Learning, hubris and corporate serial acquisitions, Journal of Corporate Finance 15, 543-561.

Aktas, Nihat, Eric de Bodt, and Richard Roll, 2012, Learning from repetitive acquisitions: Evidence from the time between deals, Journal of Financial Economics 108, 99-117.

Ahern, Kenneth R., 2012, Bargaining power and industry dependence in mergers, Journal of Financial Economics 103, 530-550.

Almeida, Heitor, Murillo Campello, Bruno Laranjeira, and Scott Weisbenner, 2012, Corporate debt maturity and the real effects of the 2007 financial crisis, Critical Finance Review 1, 3-58.

Andrade, Gregor, Mark Mitchell, and Erik Stafford, 2001, New evidence and perspectives on mergers, Journal of Economic Perspectives 15, 103-120.

Asquith, Paul, Robert F. Bruner, and David W. Mullins Jr, 1983, The gains to bidding firms from merger, Journal of Financial Economics 11, 121-139.

Baker, Malcolm, Xin Pan, and Jeffrey Wurgler, 2012, The effect of reference point prices on mergers and acquisitions, Journal of Financial Economics 106, 49-71.

Bargeron, Leonce L., Frederik P. Schlingemann, René M. Stulz, and Chad J. Zutter, 2008, Why do private acquirers pay so little compared to public acquirers?, Journal of Financial Economics 89, $375-390$. 
Bargeron, Leonce L., Frederik P. Schlingemann, René M. Stulz, and Chad J. Zutter, 2013, Does target CEO retention in acquisitions involving private equity acquirers harm target shareholders?, Working paper, Ohio State University.

Bertrand, Marianne, Simon Johnson, Krisiert Samphantharak, and Antoinette Schoar, 2008, Mixing family with business: A study of Thai business groups and the families behind them, Journal of Financial Economics 88, 466-498.

Betton, Sandra, B. Espen Eckbo, and Karin S. Thorburn, 2008, Corporate Takeovers, B.E. Eckbo, Editor, Handbook of Corporate Finance, Empirical Corporate Finance vol. 2, Elsevier, North-Holland, Amsterdam (2008), 291-429.

Black, Bernard S., 1989, Bidder overpayment in takeovers, Stanford Law Review 41, 597-653.

Boone, Audra L., and J. Harold Mulherin, 2007, How are firms sold?, Journal of Finance 62, 847-875.

Boone, Audra L., and J. Harold Mulherin, 2008, Do auctions induce a winner's curse? New evidence from the corporate takeover market, Journal of Financial Economics 89, 1-19.

Bradley, Michael, Anand Desai, and E. Han Kim, 1988, Synergistic gains from corporate acquisitions and their division between the stockholders of target and acquiring firms, Journal of Financial Economics $21,3-40$.

Brown, Stephen J., and Jerold B. Warner, 1985, Using daily stock returns: The case of event studies, Journal of Financial Economics 14, 3-31.

Cai, Jie, Moon H. Song, and Ralph A. Walkling, 2011, Anticipation, acquisitions, and bidder returns: Industry shocks and the transfer of information across rivals, Review of Financial Studies 24, 22422285 .

Cai, Jie, and Anand M. Vijh, 2007, Incentive effects of illiquid stock and option holdings of target and acquirer CEOs, Journal of Finance 62, 1891-1933.

Cain, Matthew D., David J. Denis, and Diane K. Denis, 2011, Earnouts: A study of financial contracting in acquisition agreements, Journal of Accounting and Economics 51, 151-170. 
Campa, José M., and Simi Kedia, 2002, Explaining the diversification discount, Journal of Finance 57, $1731-1762$.

Chang, Saeyoung, 1998, Takeovers of privately held targets, method of payment, and bidder returns, Journal of Finance 53, 773-784.

Cliff, Michael T., and David J. Denis, 2004, Do initial public offering firms purchase analyst coverage with underpricing?, Journal of Finance 59, 2871-2901.

Fahlenbrach, Rüdiger, 2009, Founder-CEOs, investment decisions, and stock market performance, Journal of Financial and Quantitative Analysis 44, 439-466.

Fang, Lily H., 2005, Investment bank reputation and the price and quality of underwriting services, Journal of Finance 60, 2729-2761.

Fuller, Kathleen, Jeffry M. Netter, and Mike Stegemoller, 2002, What do returns to acquiring firms tell us? Evidence from firms that make many acquisitions, Journal of Finance 57, 1763-1793.

Golubov, Andrey, Dimitris Petmezas, and Nickolaos G. Travlos, 2012, When it pays to pay your investment banker: New evidence on the role of financial advisors in M\&As, Journal of Finance 67, 271-312.

Heckman, James J., 1978, Dummy endogenous variables in a simultaneous equations system, Econometrica 46, 931-959.

Heckman, James J., 1979, Sample selection bias as a specification error, Econometrica 47, 153-161.

Hietala, Pekka, Steven N. Kaplan, and David T. Robinson, 2003, What is the price of hubris? Using takeover battles to infer overpayments and synergies, Financial Management 32, 5-31.

Jovanovic, Boyan, and Serguey Braguinsky, 2004, Bidder discounts and target premia in takeovers, American Economic Review 94, 46-56.

Kahle, Kathleen M., and Ralph A. Walkling, 1996, The impact of industry classifications on financial research, Journal of Financial and Quantitative Analysis 31, 309-335.

Kale, Jayant R., Omesh Kini, and Harley E. Ryan Jr, 2003, Financial advisors and shareholder wealth gains in corporate takeovers, Journal of Financial and Quantitative Analysis 38, 475-501. 
Kaplan, Steven N., Mark M. Klebanov, and Morten Sorensen, 2012, Which CEO characteristics and abilities matter?, Journal of Finance 67 , 973-1007.

Kini, Omesh, William Kracaw, and Shehzad Mian, 2004, The nature of discipline by corporate takeovers, Journal of Finance 59, 1511-1552.

Klasa, S., 2009, Why do controlling families of public firms sell their remaining ownership stake?, Journal of Financial and Quantitative Analysis 42, 339-368.

Lee, Young Han, and Ulrike Malmendier, 2011, The bidder's curse, American Economic Review 101, 749-787.

Li, Feng, and Suraj Srinivasan, 2011, Corporate governance when founders are directors, Journal of Financial Economics 102, 454-469.

Lokshin, Michael, and Zurab Sajaia, 2004, Maximum likelihood estimation of endogenous switching regression models, The Stata Journal 4-3, 282-289.

Loughran, Tim, and Jay Ritter, 2004, Why has IPO underpricing changed over time?, Financial Management 33, 5-37.

Malatesta, Paul H., 1983, The wealth effect of merger activity and the objective functions of merging firms, Journal of Financial Economics 11, 155-181.

Malmendier, Ulrike, and Geoffrey Tate, 2008, Who makes acquisitions? CEO overconfidence and the market's reaction, Journal of Financial Economics 89, 20-43.

Martin, Kenneth J., and John J. McConnell, 1991, Corporate performance, corporate takeovers, and management turnover, Journal of Finance 46, 671-687.

McCardle, Kevin F., and S. Viswanathan, 1994, The direct entry versus takeover decision and stock price performance around takeovers, Journal of Business 67, 1-43.

Mitchell, Mark, Todd Pulvino, and Erik Stafford, 2004, Price pressure around mergers, Journal of Finance 59, 31-63.

Moeller, Thomas, 2005, Let's make a deal! How shareholder control impacts merger payoffs, Journal of Financial Economics 76, 167-190. 
Moeller, Sara B., Frederik P. Schlingemann, and René M. Stulz, 2004, Firm size and the gains from acquisitions, Journal of Financial Economics 73, 201-228.

Moeller, Sara B., Frederik P. Schlingemann, and René M. Stulz, 2005, Wealth destruction on a massive scale? A study of acquiring firms in the recent merger wave, Journal of Finance 60, 757-782.

Moeller, Sara B., Frederik P. Schlingemann, and René M. Stulz, 2007, How do diversity of opinion and information asymmetry affect acquirer returns?, Review of Financial Studies 20, 2047-2078.

Netter, Jeffry, Mike Stegemoller, and M. Babajide Wintoki, 2011, Implications of data screens on merger and acquisition analysis: A large sample study of mergers and acquisitions from 1992 to 2009 , Review of Financial Studies 24, 2316-2357.

Officer, Micah S., Annette B. Poulsen, and Mike Stegemoller, 2009, Target-firm information asymmetry and acquirer returns, Review of Finance 13, 467-493.

Palia, Darius, S. Abraham Ravid, and Chia-Jane Wang, 2008, Founders versus non-founders in large companies: Financial incentives and the call for regulation, Journal of Regulatory Economics 33, 5586.

Pérez-González, Francisco, 2006, Inherited control and firm performance, American Economic Review $96,1559-1588$.

Roberts, Michael R., and Toni M. Whited, 2013, Endogeneity in Empirical Corporate Finance, George M. Constantinides, Milton Harris, and Rene M. Stulz, Editors, Handbook of the Economics of Finance vol. 2, Elsevier, North-Holland, Amsterdam (2013), 493-572.

Roll, Richard, 1986, The hubris hypothesis of corporate takeovers, Journal of Business 59, 197-216.

Schlingemann, Frederik P., René M. Stulz, and Ralph A. Walkling, 2002, Divestitures and the liquidity of the market for corporate assets, Journal of Financial Economics 64, 117-144.

Schwert, G. William, 1996, Markup pricing in mergers and acquisitions, Journal of Financial Economics 41, 153-192.

Servaes, Henri, 1991, Tobin's Q and the gains from takeovers, Journal of Finance 46, 409-419. 
Song, Moon H., and Ralph A. Walkling, 1993, The impact of managerial ownership on acquisition attempts and target shareholder wealth, Journal of Financial and Quantitative Analysis 28, 439-457.

Travlos, Nickolaos G., 1987, Corporate takeover bids, methods of payment, and bidding firms' stock returns, Journal of Finance 42, 943-963.

Villalonga, Belén, and Raphael Amit, 2006, How do family ownership, control and management affect firm value?, Journal of Financial Economics 80, 385-417.

Wooldridge, Jeffrey M., 2002, Econometric analysis of cross section and panel data, MIT Press, Cambridge, MA (2002).

Wulf, Julie, and Harbir Singh, 2011, How do acquirers retain successful target CEOs? The role of governance, Management Science 57, 2101-2114. 


\section{Appendix: Variable Definitions}

Variable

100\% cash payment

100\% stock payment

Bidder BHAR (-1, eff)

Bidder CAR $(-1,+1)$

Capital expenditures/PPE

Cash/Assets

CEO age

CEO age $>60$

CEO CF right

CEO departure

CEO tenure

CEO voting right

Days to completion

Deal value

Debt/Assets

Delaware

Diversifying deal

Dividends/BVE
Definition

Indicator variable equal to one if the deal is financed using only cash

Indicator variable equal to one if the deal is financed using only stock

Bidder's buy-and-hold abnormal return from one day before the deal's announcement date to the deal's effective date, based on Fama-French-Carhart 4-factor model parameters estimated using observations from -379 to -127 trading days relative to the deal's announcement, following Schwert (1996)

Bidder's 3-day cumulative abnormal return around the deal's announcement date, based on market model parameters estimated using observations from -379 to -127 trading days relative to the deal's announcement, following Schwert (1996)

Capital expenditures (including amounts arising from acquisitions) divided by net property, plant and equipment

Cash and short-term investments divided by total assets

Age of the target's CEO in years

Indicator variable equal to one if the age of the target's CEO is greater than 60 years

Cash-flow right of the target's CEO in the company as a percentage of total shares outstanding, derived from the proxy filing prior but closest to the deal's announcement

Indicator variable equal to one if the CEO is no longer an employee of the merged entity within two years after the effective date and zero otherwise.

Tenure of the target's CEO in years

Voting right of the target's CEO in the company as a percentage of total votes outstanding, derived from the proxy filing prior but closest to the deal's announcement

Number of days between the deal's announcement date and effective date

Total value of consideration paid by the bidder excluding fees and expenses

Book value of debt divided by total assets

Indicator variable equal to one if the target is incorporated in Delaware

Indicator variable equal to one if the deal involves a target with a two-digit SIC code other than that of the bidder

Total dividends paid to book value of equity 
Early Incorporation

FHC

Firm age

Founder CEO

Growth in sales

High tech

Idiosyncratic risk

Months on CRSP

Multiple bidders

Multiple class share structure

MVE

Operating income/Assets

$R \& D /$ Sales

Relative size

Relative change in $Q$

S\&P 500

Sales

Serial acquirer
Indicator variable equal to one if the target is incorporated before 1950 and zero otherwise

Difference between the actual Q of a target if the company employs the founder in the CEO position and the hypothetical Q of the target had the company not employed the founder. It is equal to zero for a target if the founder is not employed in the company

Number of years between the target's inception and the deal's announcement

Indicator variable equal to one if the target's founder is the company's CEO

Percentage change in annual sales prior to the deal announcement

Indicator variable equal to one if the company belongs to high technology industry defined as SIC codes 2833, 2834, 2835, 2836 (drugs), 3571, 3572, 3575, 3577, 3578 (computer hardware), 3661, 3663, 3669 (communications equipment), 3674 (electronics), 3812 (navigation equipment), 3823, 3825, 3826, 3827, 3829 (measuring and controlling devices), 4812, 4813, 4899 (communication services), and 7370, 7371, 7372, 7373, 7374, 7375, 7377, 7378, 7379 (software)

Standard deviation of the target's residuals derived from the market model using observations from -379 to -127 trading days relative to the deal's announcement, following Schwert (1996)

Number of months between the first listing on CRSP and the deal's announcement of the target firm

Indicator variable equal to one if there is at least one company that bid for the target after the initial bidder

Indicator variable equal to one if the target has more than one class of shares with different voting rights, as reported in the proxy filing prior but closest to the deal's announcement

Market value of equity calculated as share price $\times$ number of shares outstanding at -22 trading days relative to the deal's announcement

Operating income before depreciation divided by total assets

Research and development expenses divided by sales, replaced with zero for missing values

Target's total assets divided by bidder's total assets

The one-year relative change in the target's Tobin's Q, based on the Tobin's Q at 22 trading days prior to the deal's announcement and the Tobin's Q at 274 days prior to the deal's announcement

Indicator variable equal to one if the target is a component of the S\&P 500 Index

Net sales

Indicator variable equal to one if the deal is the fifth deal or more announced by the bidder in the three years prior to the deal's announcement date 
Synergy CAR $(-1,+1)$

Systematic risk

Target CAR $(-1,+1)$

Target's Tobin's Q net of FHC

Tender offer

Tobin's $Q(Q)$

Total assets

TPROP
MVE-weighted bidder's and target's 3-day cumulative abnormal return around the deal's announcement, based on market model parameters estimated using observations from -379 to -127 trading days relative to the deal's announcement, following Schwert (1996)

Slope derived from the market model using observations from -379 to -127 trading days relative to the deal's announcement, following Schwert (1996)

Target's 3-day cumulative abnormal return around the deal's announcement date, based on market model parameters estimated using observations from -379 to -127 trading days relative to the deal's announcement, following Schwert (1996)

Difference between the actual Q and the FHC of a target

Indicator variable equal to one if the deal is a tender offer

Market value of assets divided by book value of assets, where the market value of assets is MVE plus the book value of assets minus the book value of equity and the deferred taxes

Book value of assets

Measure of the target's relative wealth gain used in Kale et al. (2003) winsorized at $1^{\text {st }}$ and $99^{\text {th }}$ percentiles 


\section{Table 1}

Number of deals by presence and type of target's founder over time

The sample includes all SDC completed merger and acquisition deals between a U.S. public bidder and a U.S. public target announced between 1997 and 2008. The deals start with at most 50\% and result in $100 \%$ ownership by the bidder, where the book value of assets (BVA) of the target is at least $\$ 100$ million; the BVA of the target relative to the BVA of the bidder is at least $1 \%$; and the target founder information is available. The sample is based on availability of firm-, deal-, and CEO-specific data used in the analysis. The percentages are based on all the observations within the given year.

\begin{tabular}{cccccccc}
\hline & Full sample & & \multicolumn{2}{c}{ Non-founder } & & \multicolumn{2}{c}{ Founder CEO } \\
\cline { 2 - 3 } \cline { 7 - 8 } Year & Obs. & & Obs. & $\%$ & & Obs. & $\%$ \\
\hline 1997 & 108 & & 87 & $80.6 \%$ & & 21 & $19.4 \%$ \\
1998 & 119 & & 102 & $85.7 \%$ & & 17 & $14.3 \%$ \\
1999 & 133 & & 112 & $84.2 \%$ & & 21 & $15.8 \%$ \\
2000 & 94 & & 76 & $80.9 \%$ & & 18 & $19.1 \%$ \\
2001 & 70 & & 56 & $80.0 \%$ & & 14 & $20.0 \%$ \\
2002 & 29 & & 26 & $89.7 \%$ & & 3 & $10.3 \%$ \\
2003 & 46 & & 37 & $80.4 \%$ & & 9 & $19.6 \%$ \\
2004 & 56 & & 47 & $83.9 \%$ & & 9 & $16.1 \%$ \\
2005 & 55 & & 47 & $85.5 \%$ & & 8 & $14.5 \%$ \\
2006 & 49 & & 42 & $85.7 \%$ & & 7 & $14.3 \%$ \\
2007 & 59 & & 49 & $83.1 \%$ & & 10 & $16.9 \%$ \\
2008 & 27 & & 22 & $81.5 \%$ & & 5 & $18.5 \%$ \\
\hline Total & 845 & & 703 & $83.2 \%$ & & 142 & $16.8 \%$ \\
\hline
\end{tabular}




\section{Table 2}

Summary statistics on target, bidder and deal characteristics

The sample includes all SDC completed merger and acquisition deals between a U.S. public bidder and a U.S. public target announced between 1997 and 2008. The deals start with at most $50 \%$ and result in $100 \%$ ownership by the bidder, where the book value of assets (BVA) of the target is at least $\$ 100$ million; the BVA of the target relative to the BVA of the bidder is at least $1 \%$; and the target founder information is available. All variables are defined in the Appendix. Variables are as of the deal's announcement and if unavailable, then as of a date closest but prior to the deal's announcement. Total assets, sales, MVE, and deal value are in 2008 dollars. The mean return measures denoted with ${ }^{\mathrm{a}},{ }^{\mathrm{b}}$, or $^{\mathrm{c}}$ are significant at the $1 \%, 5 \%$, or $10 \%$ level, respectively, and $p$-values are based on differences in medians and means between the non-founder and founder CEO sub-samples. For binary variables we only report the $p$-value of the mean difference between the non-founder and founder CEO sub-samples.

\begin{tabular}{|c|c|c|c|c|c|c|c|c|c|c|c|}
\hline & \multicolumn{3}{|c|}{ Full sample } & \multicolumn{3}{|c|}{ Non-founder } & \multicolumn{3}{|c|}{ Founder CEO } & \multicolumn{2}{|c|}{$p$-value } \\
\hline & Mean & Median & St.dev. & Mean & Median & St.dev. & Mean & Median & St.dev. & Mean & Mediar \\
\hline \multicolumn{12}{|l|}{ Return measures } \\
\hline Bidder CAR $(-1,+1)$ & $-0.0220^{\mathrm{a}}$ & $-0.0159^{\mathrm{a}}$ & 0.0682 & $-0.0197^{\mathrm{a}}$ & $-0.0160^{\mathrm{a}}$ & 0.0665 & $-0.0336^{\mathrm{a}}$ & $-0.0145^{\mathrm{a}}$ & 0.0753 & 0.042 & 0.404 \\
\hline Bidder BHAR (-1, eff) & $-0.0611^{\mathrm{a}}$ & $-0.0467^{\mathrm{a}}$ & 0.3103 & $-0.0542^{\mathrm{a}}$ & $-0.0467^{\mathrm{a}}$ & 0.2984 & $-0.0955^{\mathrm{a}}$ & $-0.0449^{c}$ & 0.3629 & 0.205 & 0.538 \\
\hline Synergy CAR $(-1,+1)$ & $0.0066^{\mathrm{a}}$ & 0.0029 & 0.0663 & $0.0095^{\mathrm{a}}$ & 0.0026 & 0.0647 & -0.0077 & 0.0034 & 0.0724 & 0.010 & 0.273 \\
\hline \multicolumn{12}{|l|}{ Target CEO characteristics } \\
\hline CEO age & 54.802 & 55.000 & 7.200 & 54.794 & 55.000 & 6.662 & 54.845 & 54.000 & 9.451 & 0.951 & 0.589 \\
\hline CEO age $>60$ & 0.246 & 0.000 & 0.431 & 0.239 & 0.000 & 0.427 & 0.282 & 0.000 & 0.451 & 0.282 & \\
\hline CEO tenure & 8.026 & 6.000 & 6.931 & 6.826 & 5.000 & 5.680 & 13.965 & 12.000 & 9.176 & 0.000 & 0.000 \\
\hline CEO CF right & 0.043 & 0.017 & 0.087 & 0.028 & 0.013 & 0.056 & 0.120 & 0.065 & 0.151 & 0.000 & 0.000 \\
\hline $\mathrm{CEO}$ voting right & 0.048 & 0.017 & 0.105 & 0.030 & 0.013 & 0.072 & 0.134 & 0.063 & 0.176 & 0.000 & 0.000 \\
\hline
\end{tabular}


Table 2 - continued

\begin{tabular}{|c|c|c|c|c|c|c|c|c|c|c|c|}
\hline \multirow[b]{3}{*}{ Target firm characteristics } & \multicolumn{3}{|c|}{ Full sample } & \multicolumn{3}{|c|}{ Non-founder } & \multicolumn{3}{|c|}{ Founder CEO } & \multicolumn{2}{|c|}{$p$-value } \\
\hline & Mean & Median & St.dev. & Mean & Median & St.dev. & Mean & Median & St.dev. & Mean & Median \\
\hline & & & & & & & & & & & \\
\hline Total Assets $\times \$ 100$ million & 93.590 & 10.792 & 438.530 & 104.199 & 11.968 & 470.818 & 41.069 & 7.118 & 210.119 & 0.012 & 0.000 \\
\hline Sales $\times \$ 100$ million & 23.771 & 5.039 & 62.010 & 26.301 & 5.447 & 66.539 & 11.247 & 3.767 & 27.992 & 0.000 & 0.015 \\
\hline MVE $\times \$ 100$ million & 32.831 & 7.028 & 93.597 & 35.923 & 7.013 & 101.201 & 17.395 & 7.472 & 33.131 & 0.000 & 0.717 \\
\hline Cash/Assets & 0.118 & 0.044 & 0.171 & 0.105 & 0.042 & 0.156 & 0.184 & 0.085 & 0.217 & 0.000 & 0.001 \\
\hline Debt/Assets & 0.655 & 0.683 & 0.265 & 0.681 & 0.703 & 0.256 & 0.528 & 0.551 & 0.273 & 0.000 & 0.000 \\
\hline Operating income/Assets & 0.098 & 0.101 & 0.097 & 0.094 & 0.098 & 0.098 & 0.119 & 0.110 & 0.094 & 0.006 & 0.005 \\
\hline Growth in sales & 0.170 & 0.101 & 0.355 & 0.148 & 0.090 & 0.347 & 0.274 & 0.188 & 0.376 & 0.000 & 0.000 \\
\hline Tobin's Q & 1.717 & 1.214 & 2.085 & 1.601 & 1.177 & 1.295 & 2.292 & 1.472 & 4.155 & 0.052 & 0.000 \\
\hline Capital expenditures/PPE & 0.384 & 0.195 & 1.541 & 0.367 & 0.181 & 1.008 & 0.467 & 0.350 & 3.050 & 0.707 & 0.000 \\
\hline Dividends/BVE & 0.034 & 0.015 & 0.094 & 0.038 & 0.021 & 0.099 & 0.017 & 0.000 & 0.060 & 0.001 & 0.000 \\
\hline $\mathrm{R} \& \mathrm{D} /$ Sales & 0.047 & 0.000 & 0.435 & 0.046 & 0.000 & 0.475 & 0.049 & 0.000 & 0.105 & 0.881 & 0.257 \\
\hline High tech & 0.194 & 0.000 & 0.396 & 0.166 & 0.000 & 0.373 & 0.331 & 0.000 & 0.472 & 0.000 & \\
\hline Idiosyncratic risk & 0.021 & 0.019 & 0.011 & 0.020 & 0.018 & 0.010 & 0.023 & 0.021 & 0.011 & 0.002 & 0.000 \\
\hline Systematic risk & 0.792 & 0.689 & 0.578 & 0.757 & 0.633 & 0.578 & 0.971 & 0.952 & 0.549 & 0.000 & 0.000 \\
\hline Multiple class share structure & 0.025 & 0.000 & 0.156 & 0.016 & 0.000 & 0.124 & 0.070 & 0.000 & 0.257 & 0.014 & \\
\hline Firm age & 49.539 & 29.000 & 45.784 & 56.017 & 40.000 & 47.475 & 17.556 & 16.000 & 9.453 & 0.000 & 0.000 \\
\hline Months on CRSP & 191.981 & 128.000 & 186.965 & 207.889 & 136.000 & 197.449 & 113.225 & 89.000 & 87.352 & 0.000 & 0.000 \\
\hline Delaware & 0.561 & 1.000 & 0.497 & 0.563 & 1.000 & 0.496 & 0.549 & 1.000 & 0.499 & 0.759 & \\
\hline S\&P500 & 0.149 & 0.000 & 0.356 & 0.166 & 0.000 & 0.373 & 0.063 & 0.000 & 0.245 & 0.000 & \\
\hline
\end{tabular}


Table 2 - continued

\begin{tabular}{|c|c|c|c|c|c|c|c|c|c|c|c|}
\hline & \multicolumn{3}{|c|}{ Full sample } & \multicolumn{3}{|c|}{ Non-founder } & \multicolumn{3}{|c|}{ Founder CEO } & \multicolumn{2}{|c|}{$p$-value } \\
\hline & Mean & Median & St.dev. & Mean & Median & St.dev. & Mean & Median & St.dev. & Mean & Median \\
\hline \multicolumn{12}{|l|}{ Bidder firm characteristics } \\
\hline Total Assets $\times \$ 100$ million & 352.894 & 82.326 & 1165.391 & 346.008 & 84.521 & 1058.696 & 386.985 & 69.772 & 1596.183 & 0.770 & 0.016 \\
\hline MVE $\times \$ 100$ million & 178.001 & 58.278 & 350.158 & 170.270 & 55.387 & 338.635 & 216.217 & 64.057 & 401.461 & 0.204 & 0.319 \\
\hline Cash/Assets & 0.096 & 0.041 & 0.134 & 0.091 & 0.039 & 0.132 & 0.119 & 0.063 & 0.141 & 0.020 & 0.003 \\
\hline Tobin's Q & 1.971 & 1.388 & 1.994 & 1.871 & 1.320 & 1.982 & 2.467 & 1.753 & 1.988 & 0.001 & 0.000 \\
\hline High tech & 0.195 & 0.000 & 0.397 & 0.174 & 0.000 & 0.379 & 0.303 & 0.000 & 0.461 & 0.002 & \\
\hline Serial acquirer & 0.285 & 0.000 & 0.452 & 0.289 & 0.000 & 0.454 & 0.268 & 0.000 & 0.444 & 0.611 & \\
\hline \multicolumn{12}{|l|}{ Deal characteristics } \\
\hline $100 \%$ cash payment & 0.187 & 0.000 & 0.390 & 0.178 & 0.000 & 0.383 & 0.232 & 0.000 & 0.424 & 0.128 & \\
\hline Diversifying deal & 0.711 & 1.000 & 0.453 & 0.714 & 1.000 & 0.452 & 0.697 & 1.000 & 0.461 & 0.686 & \\
\hline Multiple bidders & 0.049 & 0.000 & 0.215 & 0.054 & 0.000 & 0.226 & 0.021 & 0.000 & 0.144 & 0.027 & \\
\hline Days to completion & 149.708 & 133.000 & 92.024 & 153.610 & 135.000 & 96.359 & 130.387 & 116.500 & 63.336 & 0.000 & 0.030 \\
\hline
\end{tabular}




\section{Table 3}

Multivariate regression analysis on target average founder effect: OLS versus Treatment models

The sample includes all SDC completed merger and acquisition deals between a U.S. public bidder and a U.S. public target announced between 1997 and 2008. The deals start with at most 50\% and result in 100\% ownership by the bidder, where the book value of assets (BVA) of the target is at least $\$ 100$ million; the BVA of the target relative to the BVA of the bidder is at least 1\%; and the target founder information is available. In models (1), (3) and (5), the dependent variable is the target's Q as defined in the Appendix. Models (3) and (5) are the treatment effects model with the instrumented founder CEO as derived from models (2) and (4), respectively. In models (2) and (4), the dependent variable is an indicator variable equal to one if the target's founder is the company's CEO at the deal's announcement. All variables are defined in the Appendix. Regressions include year and industry (two-digit SIC code main classifications) fixed effects. The $p$-values are in brackets and are based on heteroskedasticityconsistent standard errors. Coefficients denoted with ${ }^{\mathrm{a}},{ }^{\mathrm{b}}$, or ${ }^{\mathrm{c}}$ are significant at the $1 \%, 5 \%$, or $10 \%$ level, respectively.

\begin{tabular}{|c|c|c|c|c|c|}
\hline & $\begin{array}{l}\mathrm{Q} \\
(1)\end{array}$ & $\begin{array}{c}\text { Founder CEO } \\
\text { (2) }\end{array}$ & $\begin{array}{l}\text { Q } \\
(3)\end{array}$ & $\begin{array}{c}\text { Founder CEO } \\
\text { (4) }\end{array}$ & $\begin{array}{l}\mathrm{Q} \\
(5)\end{array}$ \\
\hline \multirow[t]{2}{*}{ Founder CEO } & $0.6981^{\mathrm{c}}$ & & $0.9233^{\mathrm{c}}$ & & $1.0089^{b}$ \\
\hline & {$[0.071]$} & & {$[0.062]$} & & [0.041] \\
\hline \multirow[t]{2}{*}{ CEO age } & -0.0088 & $-0.0201^{b}$ & -0.0077 & -0.0145 & 0.0007 \\
\hline & {$[0.206]$} & {$[0.040]$} & {$[0.472]$} & {$[0.176]$} & [0.948] \\
\hline \multirow[t]{2}{*}{$\ln (1+\mathrm{CEO}$ tenure $)$} & 0.0559 & $0.9012^{\mathrm{a}}$ & 0.0227 & $0.9317^{\mathrm{a}}$ & -0.0441 \\
\hline & {$[0.561]$} & {$[0.000]$} & {$[0.857]$} & {$[0.000]$} & {$[0.723]$} \\
\hline \multirow[t]{2}{*}{ CEO CF right } & $-1.8296^{\mathrm{c}}$ & $5.2284^{\mathrm{a}}$ & $-2.1010^{b}$ & $5.2626^{\mathrm{a}}$ & $-2.3095^{\mathrm{b}}$ \\
\hline & [0.079] & {$[0.000]$} & {$[0.045]$} & {$[0.000]$} & {$[0.038]$} \\
\hline \multirow[t]{2}{*}{$\ln$ (Target's total assets) } & $-0.1035^{\mathrm{a}}$ & 0.0685 & -0.1051 & 0.1270 & -0.0866 \\
\hline & [0.004] & {$[0.358]$} & {$[0.120]$} & {$[0.156]$} & {$[0.236]$} \\
\hline \multirow[t]{2}{*}{$\log (1+$ Months on CRSP $)$} & $-0.1819^{b}$ & $-0.2402^{b}$ & $-0.1684^{c}$ & $-0.2389^{\mathrm{b}}$ & -0.1009 \\
\hline & {$[0.046]$} & {$[0.014]$} & {$[0.066]$} & {$[0.027]$} & [0.279] \\
\hline \multirow[t]{2}{*}{ Delaware } & 0.1696 & -0.0455 & 0.1775 & -0.1190 & 0.1593 \\
\hline & {$[0.133]$} & {$[0.770]$} & {$[0.235]$} & {$[0.483]$} & [0.292] \\
\hline \multirow[t]{2}{*}{ S\&P500 } & $0.4264^{b}$ & 0.2952 & 0.4227 & 0.1120 & 0.2745 \\
\hline & {$[0.013]$} & {$[0.356]$} & {$[0.118]$} & {$[0.752]$} & [0.321] \\
\hline \multirow[t]{2}{*}{ Early incorporation } & & $-3.1295^{\mathrm{a}}$ & & $-2.9269^{\mathrm{a}}$ & \\
\hline & & {$[0.000]$} & & {$[0.001]$} & \\
\hline \multirow[t]{2}{*}{ Debt/Assets } & & & & $-1.1678^{\mathrm{a}}$ & $-1.4736^{\mathrm{a}}$ \\
\hline & & & & {$[0.005]$} & {$[0.000]$} \\
\hline \multirow[t]{2}{*}{ Growth in sales } & & & & -0.0225 & $0.4859^{\mathrm{b}}$ \\
\hline & & & & [0.917] & [0.019] \\
\hline \multirow[t]{2}{*}{ Capital expenditures/PPE } & & & & -0.0292 & -0.0064 \\
\hline & & & & {$[0.467]$} & [0.890] \\
\hline \multirow[t]{2}{*}{ Dividends/BVE } & & & & -1.4293 & $1.3113^{\mathrm{c}}$ \\
\hline & & & & {$[0.530]$} & [0.096] \\
\hline \multirow[t]{2}{*}{$R \& D$ to sales } & & & & 0.1721 & 0.0790 \\
\hline & & & & {$[0.476]$} & [0.627] \\
\hline
\end{tabular}


Table 3 - continued

(1)

Systematic risk

Multiple class share structure

Constant

Year fixed effects

Industry fixed effects

Observations

Adjusted R-squared

McFadden's adjusted R-squared
(2)

(3)

(4)

(5)

$0.3743^{\mathrm{b}} \quad 0.3511^{\mathrm{b}}$ [0.014] [0.022]

$-0.3713 \quad 0.2198$

[0.440] [0.662]

$-1.1297 \quad 2.8954^{\mathrm{a}}$

[0.205] [0.001]

[0.000]

$-0.4808 \quad 3.6666^{\mathrm{a}}$

[0.000]

Yes $\quad$ Yes

Yes

Yes

Yes

Yes

Yes

845

845

845

821

821 


\section{Table 4}

Summary statistics on target founder CEO's human capital (FHC)

The sample includes all SDC completed merger and acquisition deals between a U.S. public bidder and a U.S. public target announced between 1997 and 2008. The deals start with at most $50 \%$ and result in $100 \%$ ownership by the bidder, where the book value of assets (BVA) of the target is at least $\$ 100$ million; the BVA of the target relative to the BVA of the bidder is at least 1\%; and the target founder information is available. Statistical significance ( $p$-values) is reported for the Median and Mean denoting the difference from zero.

\begin{tabular}{rrc} 
& FHC & $p$-value \\
\hline $25^{\text {th }}$ percentile & -0.248 & $\cdot$ \\
Median & 0.159 & 0.009 \\
$75^{\text {th }}$ percentile & 0.946 & $\cdot$ \\
Mean & 0.854 & 0.014 \\
Percent negative & $38.7 \%$ & \\
Observations & 142 & \\
& & \\
\hline
\end{tabular}




\section{Table 5}

Multiple regression analysis on bidder gains

The sample includes all SDC completed merger and acquisition deals between a U.S. public bidder and a U.S. public target announced between 1997 and 2008 . The deals start with at most $50 \%$ and result in $100 \%$ ownership by the bidder, where the book value of assets (BVA) of the target is at least $\$ 100$ million; the BVA of the target relative to the BVA of the bidder is at least 1\%; and the target founder information is available. The dependent variable is the bidder's 3-day cumulative abnormal return around the deal's announcement, based on market model parameters. All variables are defined in the Appendix. Regressions include year and industry (two-digit SIC code main classifications) fixed effects. The $p$-values are in brackets and are based on heteroskedasticity-consistent standard errors. Coefficients denoted with ${ }^{\mathrm{a}}, \mathrm{b}$, or $^{\mathrm{c}}$ are significant at the $1 \%, 5 \%$, or $10 \%$ level, respectively.

\begin{tabular}{|c|c|c|c|c|c|c|c|c|c|}
\hline & $(1)$ & $(2)$ & $(3)$ & $(4)$ & $(5)$ & $(6)$ & $(7)$ & $(8)$ & $(9)$ \\
\hline Founder CEO & $\begin{array}{r}-0.0122^{\mathrm{c}} \\
{[0.081]}\end{array}$ & $\begin{array}{r}-0.0214 \\
{[0.218]}\end{array}$ & & $\begin{array}{c}-0.0179 \\
{[0.303]}\end{array}$ & $\begin{array}{r}-0.0180 \\
{[0.300]}\end{array}$ & & & & \\
\hline FHC & & & $\begin{array}{r}-0.0040^{\mathrm{a}} \\
{[0.000]}\end{array}$ & $\begin{array}{r}-0.0038^{\mathrm{a}} \\
{[0.005]}\end{array}$ & $\begin{array}{r}-0.0037^{\mathrm{a}} \\
{[0.005]}\end{array}$ & & $\begin{array}{r}-0.0049^{\mathrm{a}} \\
{[0.000]}\end{array}$ & $\begin{array}{r}-0.0050^{\mathrm{a}} \\
{[0.000]}\end{array}$ & \\
\hline CEO departure & & & & & & & & & $\begin{array}{r}0.0060 \\
{[0.670]}\end{array}$ \\
\hline FHC | CEO departure $=0$ & & & & & & & & & $\begin{array}{c}0.0112 \\
{[0.283]}\end{array}$ \\
\hline FHC | CEO departure $=1$ & & & & & & & & & $\begin{array}{r}-0.0055^{\mathrm{a}} \\
{[0.000]}\end{array}$ \\
\hline Target's Tobin's Q net of FHC & & & & & $\begin{array}{r}0.0021 \\
{[0.347]}\end{array}$ & & & $\begin{array}{r}0.0324 \\
{[0.447]}\end{array}$ & $\begin{array}{c}0.0335 \\
{[0.426]}\end{array}$ \\
\hline CEO age & $\begin{array}{c}0.0001 \\
{[0.825]}\end{array}$ & $\begin{array}{r}0.0000 \\
{[0.905]}\end{array}$ & $\begin{array}{c}0.0001 \\
{[0.789]}\end{array}$ & $\begin{array}{c}0.0001 \\
{[0.856]}\end{array}$ & $\begin{array}{c}0.0001 \\
{[0.824]}\end{array}$ & $\begin{array}{r}0.0000 \\
{[0.996]}\end{array}$ & $\begin{array}{c}0.0002 \\
{[0.838]}\end{array}$ & $\begin{array}{r}0.0007 \\
{[0.438]}\end{array}$ & $\begin{array}{c}0.0006 \\
{[0.459]}\end{array}$ \\
\hline CEO CF right & $\begin{array}{r}0.0433 \\
{[0.159]}\end{array}$ & $\begin{array}{r}0.0590 \\
{[0.138]}\end{array}$ & $\begin{array}{r}0.0290 \\
{[0.316]}\end{array}$ & $\begin{array}{r}0.0578 \\
{[0.144]}\end{array}$ & $\begin{array}{r}0.0623 \\
{[0.118]}\end{array}$ & $\begin{array}{c}0.0279 \\
{[0.489]}\end{array}$ & $\begin{array}{r}0.0214 \\
{[0.587]}\end{array}$ & $\begin{array}{c}0.0687 \\
{[0.346]}\end{array}$ & $\begin{array}{c}0.0514 \\
{[0.474]}\end{array}$ \\
\hline Multiple class share structure & $\begin{array}{r}0.0047 \\
{[0.784]}\end{array}$ & $\begin{array}{c}0.0073 \\
{[0.640]}\end{array}$ & $\begin{array}{r}0.0040 \\
{[0.816]}\end{array}$ & $\begin{array}{r}0.0065 \\
{[0.675]}\end{array}$ & $\begin{array}{r}0.0059 \\
{[0.703]}\end{array}$ & $\begin{array}{l}-0.0138 \\
{[0.492]}\end{array}$ & $\begin{array}{l}-0.0168 \\
{[0.464]}\end{array}$ & $\begin{array}{l}-0.0200 \\
{[0.386]}\end{array}$ & $\begin{array}{r}-0.0240 \\
{[0.264]}\end{array}$ \\
\hline $\ln$ (Bidder's total assets) & $\begin{array}{r}-0.0007 \\
{[0.740]}\end{array}$ & $\begin{array}{r}0.0000 \\
{[0.998]}\end{array}$ & $\begin{array}{r}-0.0005 \\
{[0.819]}\end{array}$ & $\begin{array}{c}0.0003 \\
{[0.875]}\end{array}$ & $\begin{array}{c}0.0002 \\
{[0.904]}\end{array}$ & $\begin{array}{c}0.0014 \\
{[0.850]}\end{array}$ & $\begin{array}{r}0.0060 \\
{[0.379]}\end{array}$ & $\begin{array}{r}0.0077 \\
{[0.300]}\end{array}$ & $\begin{array}{r}0.0087 \\
{[0.248]}\end{array}$ \\
\hline Bidder's cash/assets & $\begin{array}{r}-0.0380 \\
{[0.115]}\end{array}$ & $\begin{array}{r}-0.0435^{\mathrm{b}} \\
{[0.039]}\end{array}$ & $\begin{array}{r}-0.0400^{\mathrm{c}} \\
{[0.094]}\end{array}$ & $\begin{array}{r}-0.0462^{b} \\
{[0.028]}\end{array}$ & $\begin{array}{r}-0.0445^{b} \\
{[0.035]}\end{array}$ & $\begin{array}{l}-0.0611 \\
{[0.488]}\end{array}$ & $\begin{array}{l}-0.0982 \\
{[0.244]}\end{array}$ & $\begin{array}{l}-0.1063 \\
{[0.225]}\end{array}$ & $\begin{array}{r}-0.1071 \\
{[0.215]}\end{array}$ \\
\hline
\end{tabular}


Table 5 - continued

\begin{tabular}{|c|c|c|c|c|c|c|c|c|c|}
\hline & (1) & (2) & (3) & (4) & (5) & (6) & (7) & (8) & (9) \\
\hline \multirow[t]{2}{*}{ Bidder's debt/assets } & 0.0300 & 0.0251 & 0.0270 & 0.0203 & 0.0223 & 0.0187 & -0.0297 & -0.0301 & -0.0447 \\
\hline & {$[0.152]$} & {$[0.135]$} & {$[0.186]$} & [0.229] & [0.189] & {$[0.806]$} & {$[0.648]$} & {$[0.643]$} & {$[0.503]$} \\
\hline \multirow[t]{2}{*}{ Bidder's Tobin's Q } & $-0.0045^{\mathrm{a}}$ & $-0.0046^{\mathrm{a}}$ & $-0.0045^{\mathrm{a}}$ & $-0.0045^{\mathrm{a}}$ & $-0.0050^{\mathrm{a}}$ & -0.0108 & -0.0086 & -0.0084 & -0.0093 \\
\hline & {$[0.010]$} & [0.001] & [0.008] & [0.002] & [0.001] & {$[0.136]$} & {$[0.219]$} & {$[0.231]$} & {$[0.195]$} \\
\hline \multirow[t]{2}{*}{ Relative size } & 0.0014 & 0.0024 & 0.0013 & 0.0020 & 0.0029 & -0.0104 & -0.0130 & -0.0108 & -0.0091 \\
\hline & {$[0.755]$} & {$[0.538]$} & {$[0.774]$} & {$[0.603]$} & {$[0.466]$} & {$[0.562]$} & {$[0.466]$} & {$[0.548]$} & {$[0.629]$} \\
\hline \multirow[t]{2}{*}{ Tender offer } & 0.0129 & $0.0144^{c}$ & 0.0117 & $0.0134^{c}$ & $0.0139^{\mathrm{c}}$ & 0.0075 & 0.0040 & 0.0045 & 0.0054 \\
\hline & {$[0.128]$} & {$[0.053]$} & {$[0.167]$} & [0.069] & {$[0.061]$} & {$[0.750]$} & {$[0.857]$} & {$[0.843]$} & {$[0.816]$} \\
\hline \multirow[t]{2}{*}{$100 \%$ stock payment } & -0.0012 & -0.0000 & -0.0004 & 0.0008 & 0.0004 & -0.0211 & -0.0150 & -0.0144 & -0.0202 \\
\hline & {$[0.841]$} & [0.997] & {$[0.950]$} & {$[0.886]$} & {$[0.947]$} & {$[0.285]$} & {$[0.436]$} & {$[0.459]$} & {$[0.317]$} \\
\hline \multirow[t]{2}{*}{$100 \%$ cash payment } & $0.0324^{\mathrm{a}}$ & $0.0319^{\mathrm{a}}$ & $0.0319^{\mathrm{a}}$ & $0.0316^{\mathrm{a}}$ & $0.0317^{\mathrm{a}}$ & $0.0324^{\mathrm{c}}$ & 0.0236 & 0.0233 & 0.0205 \\
\hline & {$[0.000]$} & {$[0.000]$} & {$[0.000]$} & {$[0.000]$} & {$[0.000]$} & {$[0.094]$} & {$[0.221]$} & {$[0.234]$} & {$[0.287]$} \\
\hline \multirow[t]{2}{*}{ Diversifying deal } & 0.0022 & 0.0037 & 0.0027 & 0.0041 & 0.0042 & 0.0168 & 0.0214 & 0.0239 & 0.0257 \\
\hline & [0.698] & {$[0.474]$} & {$[0.633]$} & {$[0.426]$} & {$[0.412]$} & {$[0.321]$} & {$[0.193]$} & {$[0.179]$} & {$[0.144]$} \\
\hline \multirow[t]{2}{*}{ Multiple bidders } & $-0.0191^{\mathrm{c}}$ & $-0.0189^{\mathrm{c}}$ & -0.0187 & $-0.0192^{\mathrm{c}}$ & $-0.0195^{\mathrm{c}}$ & -0.0184 & -0.0220 & -0.0211 & -0.0261 \\
\hline & {$[0.100]$} & [0.079] & {$[0.110]$} & [0.074] & [0.069] & {$[0.733]$} & {$[0.703]$} & {$[0.711]$} & {$[0.651]$} \\
\hline \multirow[t]{2}{*}{ Constant } & -0.0211 & -0.0410 & -0.0227 & -0.0419 & -0.0473 & -0.0307 & -0.0411 & -0.1192 & -0.1179 \\
\hline & {$[0.433]$} & {$[0.157]$} & {$[0.397]$} & {$[0.146]$} & {$[0.107]$} & {$[0.650]$} & {$[0.545]$} & {$[0.313]$} & {$[0.315]$} \\
\hline Year fixed effects & Yes & Yes & Yes & Yes & Yes & Yes & Yes & Yes & Yes \\
\hline Industry fixed effects & Yes & Yes & Yes & Yes & Yes & Yes & Yes & Yes & Yes \\
\hline Observations & 845 & 845 & 845 & 845 & 845 & 142 & 142 & 142 & 142 \\
\hline Adjusted R-squared & $10.1 \%$ & & $10.7 \%$ & & & $7.2 \%$ & $13.0 \%$ & $12.7 \%$ & $12.7 \%$ \\
\hline
\end{tabular}




\section{Table 6}

Multiple regression analysis on bidder buy-and-hold abnormal returns

The sample includes all SDC completed merger and acquisition deals between a U.S. public bidder and a U.S. public target announced between 1997 and 2008 . The deals start with at most $50 \%$ and result in $100 \%$ ownership by the bidder, where the book value of assets (BVA) of the target is at least $\$ 100$ million; the BVA of the target relative to the BVA of the bidder is at least 1\%; and the target founder information is available. The dependent variable is the bidder's buyand-hold abnormal return from one day before the deal's announcement until the deal's completion, based on Fama-French-Carhart 4-factor model parameters. All variables are defined in the Appendix. Regressions include year and industry (two-digit SIC code main classifications) fixed effects. The $p$-values are in brackets and are based on heteroskedasticity-consistent standard errors. Coefficients denoted with ${ }^{\mathrm{a}}$, ${ }^{\mathrm{b}}$, or ${ }^{\mathrm{c}}$ are significant at the $1 \%, 5 \%$, or $10 \%$ level, respectively.

\begin{tabular}{lcccccccc}
\hline & $(1)$ & $(2)$ & $(3)$ & $(4)$ & \multicolumn{1}{c}{$(5)$} & $(6)$ & $(7)$ & $(8)$ \\
\hline Founder CEO & -0.0200 & 0.0900 & & 0.1146 & 0.1157 & & & \\
& {$[0.601]$} & {$[0.267]$} & & {$[0.154]$} & {$[0.149]$} & & & \\
FHC & & & $-0.0259^{\mathrm{a}}$ & $-0.0262^{\mathrm{a}}$ & $-0.0268^{\mathrm{a}}$ & & $-0.0257^{\mathrm{a}}$ & $-0.0269^{\mathrm{a}}$ \\
& & & {$[0.000]$} & {$[0.000]$} & {$[0.000]$} & & {$[0.000]$} & {$[0.000]$} \\
Target's Tobin's Q net of FHC & & & & & $-0.0200^{\mathrm{b}}$ & & & 0.3280 \\
& & & & & {$[0.045]$} & & & {$[0.186]$} \\
CEO age & 0.0002 & 0.0001 & 0.0003 & 0.0002 & 0.0001 & -0.0070 & -0.0061 & -0.0008 \\
& {$[0.909]$} & {$[0.964]$} & {$[0.844]$} & {$[0.891]$} & {$[0.959]$} & {$[0.296]$} & {$[0.353]$} & {$[0.883]$} \\
CEO cash-flow rights & -0.1255 & -0.2961 & -0.1252 & $-0.3045^{\mathrm{c}}$ & $-0.3492^{\mathrm{c}}$ & 0.0919 & 0.0574 & 0.5363 \\
& {$[0.423]$} & {$[0.109]$} & {$[0.382]$} & {$[0.096]$} & {$[0.058]$} & {$[0.742]$} & {$[0.839]$} & {$[0.309]$} \\
Multiple class share structure & $0.1837^{\mathrm{b}}$ & $0.1783^{\mathrm{b}}$ & $0.1770^{\mathrm{b}}$ & $0.1729^{\mathrm{b}}$ & $0.1787^{\mathrm{b}}$ & $0.3084^{\mathrm{c}}$ & 0.2922 & 0.2599 \\
& {$[0.033]$} & {$[0.014]$} & {$[0.041]$} & {$[0.016]$} & {$[0.013]$} & {$[0.096]$} & {$[0.125]$} & {$[0.130]$} \\
ln(Bidder's total assets) & -0.0035 & -0.0056 & -0.0018 & -0.0037 & -0.0031 & -0.0202 & 0.0037 & 0.0211 \\
& {$[0.678]$} & {$[0.499]$} & {$[0.828]$} & {$[0.653]$} & {$[0.711]$} & {$[0.554]$} & {$[0.900]$} & {$[0.468]$} \\
Bidder's cash/assets & -0.1704 & -0.1356 & -0.1877 & -0.1537 & $-0.1697^{\mathrm{c}}$ & -0.5275 & -0.7233 & -0.8055 \\
& {$[0.232]$} & {$[0.168]$} & {$[0.181]$} & {$[0.115]$} & {$[0.083]$} & {$[0.330]$} & {$[0.167]$} & {$[0.144]$} \\
Bidder's debt/assets & 0.0939 & 0.1281 & 0.0592 & 0.0944 & 0.0745 & 0.2859 & 0.0303 & 0.0261 \\
& {$[0.333]$} & {$[0.102]$} & {$[0.488]$} & {$[0.226]$} & {$[0.343]$} & {$[0.425]$} & {$[0.914]$} & {$[0.924]$} \\
Bidder's Tobin's Q & $-0.0242^{\mathrm{a}}$ & $-0.0246^{\mathrm{a}}$ & $-0.0236^{\mathrm{a}}$ & $-0.0241^{\mathrm{a}}$ & $-0.0193^{\mathrm{a}}$ & -0.0096 & 0.0017 & 0.0039 \\
& {$[0.005]$} & {$[0.000]$} & {$[0.005]$} & {$[0.000]$} & {$[0.006]$} & {$[0.708]$} & {$[0.943]$} & {$[0.876]$} \\
\hline
\end{tabular}


Table 6 - continued

\begin{tabular}{|c|c|c|c|c|c|c|c|c|}
\hline & $(1)$ & $(2)$ & (3) & $(4)$ & (5) & $(6)$ & (7) & $(8)$ \\
\hline \multirow[t]{2}{*}{ Relative size } & 0.0065 & 0.0076 & 0.0039 & 0.0050 & -0.0036 & 0.0863 & 0.0724 & 0.0953 \\
\hline & {$[0.769]$} & {$[0.672]$} & {$[0.860]$} & {$[0.779]$} & {$[0.843]$} & {$[0.377]$} & {$[0.464]$} & [0.306] \\
\hline \multirow[t]{2}{*}{ Tender offer } & -0.0037 & -0.0038 & -0.0103 & -0.0103 & -0.0147 & 0.1023 & 0.0842 & 0.0889 \\
\hline & [0.917] & {$[0.913]$} & {$[0.767]$} & {$[0.764]$} & {$[0.668]$} & {$[0.462]$} & {$[0.544]$} & {$[0.523]$} \\
\hline \multirow[t]{2}{*}{$100 \%$ stock payment } & 0.0184 & 0.0173 & 0.0239 & 0.0230 & 0.0272 & -0.0248 & 0.0070 & 0.0135 \\
\hline & {$[0.494]$} & {$[0.510]$} & {$[0.367]$} & {$[0.377]$} & {$[0.297]$} & {$[0.808]$} & {$[0.944]$} & [0.894] \\
\hline \multirow[t]{2}{*}{$100 \%$ cash payment } & $0.1180^{\mathrm{a}}$ & $0.1167^{\mathrm{a}}$ & $0.1160^{\mathrm{a}}$ & $0.1146^{\mathrm{a}}$ & $0.1127^{\mathrm{a}}$ & 0.1163 & 0.0699 & 0.0673 \\
\hline & {$[0.000]$} & {$[0.000]$} & {$[0.000]$} & {$[0.000]$} & {$[0.000]$} & {$[0.193]$} & {$[0.428]$} & {$[0.457]$} \\
\hline \multirow[t]{2}{*}{ Diversifying deal } & 0.0355 & 0.0368 & $0.0390^{\mathrm{c}}$ & $0.0395^{\mathrm{c}}$ & 0.0383 & 0.0574 & 0.0815 & 0.1072 \\
\hline & {$[0.110]$} & {$[0.126]$} & {$[0.076]$} & {$[0.097]$} & {$[0.107]$} & {$[0.499]$} & {$[0.324]$} & {$[0.240]$} \\
\hline \multirow[t]{2}{*}{ Multiple bidders } & 0.0225 & 0.0339 & 0.0204 & 0.0323 & 0.0358 & -0.0099 & -0.0288 & -0.0194 \\
\hline & {$[0.732]$} & {$[0.500]$} & {$[0.756]$} & {$[0.517]$} & {$[0.471]$} & {$[0.968]$} & {$[0.912]$} & {$[0.942]$} \\
\hline \multirow[t]{2}{*}{ Constant } & $-0.3308^{b}$ & -0.2082 & $-0.3383^{b}$ & -0.2146 & -0.1617 & 0.3753 & 0.3206 & -0.4694 \\
\hline & {$[0.015]$} & {$[0.122]$} & {$[0.012]$} & {$[0.108]$} & {$[0.234]$} & {$[0.386]$} & {$[0.458]$} & [0.467] \\
\hline Year fixed effects & Yes & Yes & Yes & Yes & Yes & Yes & Yes & Yes \\
\hline Industry fixed effects & Yes & Yes & Yes & Yes & Yes & Yes & Yes & Yes \\
\hline Observations & 845 & 845 & 845 & 845 & 845 & 142 & 142 & 142 \\
\hline Adjusted R-squared & $5.7 \%$ & & $7.7 \%$ & & & $-5.6 \%$ & $1.5 \%$ & $2.7 \%$ \\
\hline
\end{tabular}




\section{Table 7}

Multiple regression analysis on synergy returns

The sample includes all SDC completed merger and acquisition deals between a U.S. public bidder and a U.S. public target announced between 1997 and 2008 . The deals start with at most $50 \%$ and result in $100 \%$ ownership by the bidder, where the book value of assets (BVA) of the target is at least $\$ 100$ million; the BVA of the target relative to the BVA of the bidder is at least 1\%; and the target founder information is available. The dependent variable is the 3-day synergy return around the deal's announcement, based on market model parameters. All variables are defined in the Appendix. Regressions include year and industry (two-digit SIC code main classifications) fixed effects. The $p$-values are in brackets and are based on heteroskedasticity-consistent standard errors. Coefficients denoted with ${ }^{\mathrm{a}},{ }^{\mathrm{b}}$, or $^{\mathrm{c}}$ are significant at the $1 \%, 5 \%$, or $10 \%$ level, respectively.

\begin{tabular}{|c|c|c|c|c|c|c|c|c|}
\hline & $(1)$ & $(2)$ & (3) & (4) & $(5)$ & $(6)$ & (7) & $(8)$ \\
\hline \multirow[t]{2}{*}{ Founder CEO } & -0.0099 & -0.0236 & & -0.0212 & -0.0205 & & & \\
\hline & [0.129] & {$[0.165]$} & & {$[0.212]$} & {$[0.226]$} & & & \\
\hline \multirow[t]{2}{*}{ FHC } & & & $-0.0030^{\mathrm{a}}$ & $-0.0028^{\mathrm{b}}$ & $-0.0026^{\mathrm{b}}$ & & $-0.0041^{\mathrm{a}}$ & $-0.0041^{\mathrm{a}}$ \\
\hline & & & {$[0.000]$} & {$[0.032]$} & {$[0.048]$} & & {$[0.000]$} & {$[0.000]$} \\
\hline \multirow[t]{2}{*}{ Target's Tobin's Q net of FHC } & & & & & $0.0045^{\mathrm{b}}$ & & & 0.0286 \\
\hline & & & & & {$[0.036]$} & & & {$[0.545]$} \\
\hline \multirow[t]{2}{*}{ CEO age } & 0.0001 & 0.0001 & 0.0001 & 0.0001 & 0.0001 & -0.0002 & -0.0002 & 0.0003 \\
\hline & {$[0.734]$} & {$[0.742]$} & [0.702] & [0.694] & {$[0.634]$} & {$[0.743]$} & {$[0.845]$} & {$[0.732]$} \\
\hline \multirow[t]{2}{*}{ CEO CF right } & 0.0144 & 0.0384 & 0.0023 & 0.0376 & 0.0462 & 0.0303 & 0.0290 & 0.0703 \\
\hline & [0.694] & {$[0.318]$} & [0.948] & {$[0.326]$} & {$[0.229]$} & {$[0.550]$} & {$[0.554]$} & [0.391] \\
\hline \multirow[t]{2}{*}{ Target's cash/assets } & -0.0042 & -0.0033 & 0.0004 & 0.0023 & -0.0027 & -0.0320 & -0.0127 & -0.0136 \\
\hline & {$[0.828]$} & {$[0.856]$} & [0.983] & [0.897] & {$[0.881]$} & {$[0.488]$} & {$[0.779]$} & {$[0.767]$} \\
\hline \multirow[t]{2}{*}{ Target's debt/assets } & 0.0058 & 0.0024 & 0.0064 & 0.0015 & 0.0026 & -0.0345 & -0.0465 & -0.0437 \\
\hline & {$[0.657]$} & {$[0.851]$} & [0.630] & [0.909] & {$[0.839]$} & {$[0.391]$} & {$[0.245]$} & {$[0.277]$} \\
\hline \multirow[t]{2}{*}{ Multiple class share structure } & -0.0020 & -0.0014 & -0.0023 & -0.0018 & -0.0032 & -0.0279 & -0.0291 & -0.0319 \\
\hline & {$[0.897]$} & {$[0.926]$} & [0.878] & {$[0.902]$} & {$[0.829]$} & {$[0.183]$} & {$[0.183]$} & [0.167] \\
\hline \multirow[t]{2}{*}{$\ln$ (Bidder's total assets) } & -0.0030 & -0.0026 & -0.0029 & -0.0024 & -0.0025 & 0.0022 & 0.0061 & 0.0074 \\
\hline & {$[0.145]$} & [0.139] & {$[0.165]$} & {$[0.172]$} & {$[0.147]$} & {$[0.754]$} & {$[0.358]$} & {$[0.315]$} \\
\hline \multirow[t]{2}{*}{ Bidder's cash/assets } & -0.0137 & -0.0171 & -0.0173 & -0.0217 & -0.0158 & -0.0448 & -0.0805 & -0.0871 \\
\hline & {$[0.601]$} & [0.442] & {$[0.506]$} & {$[0.328]$} & {$[0.480]$} & {$[0.616]$} & {$[0.368]$} & [0.339] \\
\hline
\end{tabular}


Table 7 - continued

\begin{tabular}{|c|c|c|c|c|c|c|c|c|}
\hline & $(1)$ & $(2)$ & $(3)$ & (4) & (5) & $(6)$ & $(7)$ & $(8)$ \\
\hline \multirow[t]{2}{*}{ Bidder's debt/assets } & 0.0335 & $0.0281^{\mathrm{c}}$ & 0.0317 & 0.0255 & $0.0290^{\mathrm{c}}$ & 0.0418 & 0.0072 & 0.0063 \\
\hline & {$[0.132]$} & {$[0.092]$} & {$[0.151]$} & {$[0.126]$} & {$[0.082]$} & {$[0.581]$} & {$[0.918]$} & [0.928] \\
\hline \multirow[t]{2}{*}{ Bidder's Tobin's Q } & $-0.0066^{\mathrm{a}}$ & $-0.0065^{\mathrm{a}}$ & $-0.0067^{\mathrm{a}}$ & $-0.0065^{\mathrm{a}}$ & $-0.0075^{\mathrm{a}}$ & $-0.0121^{\mathrm{c}}$ & -0.0111 & -0.0109 \\
\hline & {$[0.000]$} & {$[0.000]$} & {$[0.000]$} & {$[0.000]$} & {$[0.000]$} & {$[0.096]$} & {$[0.125]$} & {$[0.131]$} \\
\hline \multirow[t]{2}{*}{ Relative size } & $0.0153^{\mathrm{a}}$ & $0.0159^{\mathrm{a}}$ & $0.0154^{\mathrm{a}}$ & $0.0158^{\mathrm{a}}$ & $0.0176^{\mathrm{a}}$ & 0.0088 & 0.0101 & 0.0117 \\
\hline & {$[0.002]$} & {$[0.000]$} & {$[0.002]$} & {$[0.000]$} & {$[0.000]$} & {$[0.669]$} & {$[0.620]$} & {$[0.571]$} \\
\hline \multirow[t]{2}{*}{ Tender offer } & $0.0177^{\mathrm{b}}$ & $0.0192^{\mathrm{a}}$ & $0.0168^{b}$ & $0.0185^{\mathrm{a}}$ & $0.0195^{\mathrm{a}}$ & 0.0123 & 0.0084 & 0.0090 \\
\hline & {$[0.032]$} & {$[0.007]$} & {$[0.042]$} & {$[0.010]$} & {$[0.006]$} & {$[0.585]$} & [0.698] & {$[0.682]$} \\
\hline \multirow[t]{2}{*}{$100 \%$ stock payment } & $-0.0101^{\mathrm{c}}$ & $-0.0097^{\mathrm{c}}$ & $-0.0096^{\mathrm{c}}$ & $-0.0094^{\mathrm{c}}$ & $-0.0101^{\mathrm{c}}$ & $-0.0419^{b}$ & $-0.0382^{b}$ & $-0.0374^{b}$ \\
\hline & {$[0.071]$} & {$[0.079]$} & {$[0.086]$} & {$[0.090]$} & [0.069] & {$[0.028]$} & {$[0.038]$} & {$[0.043]$} \\
\hline \multirow[t]{2}{*}{$100 \%$ cash payment } & $0.0134^{\mathrm{b}}$ & $0.0125^{\mathrm{c}}$ & $0.0128^{\mathrm{b}}$ & $0.0118^{\mathrm{c}}$ & $0.0126^{\mathrm{c}}$ & 0.0015 & -0.0073 & -0.0072 \\
\hline & {$[0.032]$} & {$[0.070]$} & {$[0.042]$} & {$[0.086]$} & {$[0.067]$} & {$[0.937]$} & {$[0.707]$} & {$[0.718]$} \\
\hline \multirow[t]{2}{*}{ Diversifying deal } & -0.0007 & 0.0011 & -0.0003 & 0.0014 & 0.0017 & 0.0215 & 0.0259 & 0.0280 \\
\hline & {$[0.906]$} & {$[0.829]$} & {$[0.953]$} & {$[0.781]$} & {$[0.740]$} & {$[0.245]$} & {$[0.150]$} & {$[0.146]$} \\
\hline \multirow[t]{2}{*}{ Multiple bidders } & -0.0086 & -0.0093 & -0.0083 & -0.0095 & -0.0102 & -0.0477 & -0.0508 & -0.0500 \\
\hline & {$[0.467]$} & [0.379] & {$[0.484]$} & {$[0.368]$} & {$[0.330]$} & {$[0.360]$} & {$[0.328]$} & {$[0.326]$} \\
\hline \multirow[t]{2}{*}{ Constant } & 0.0076 & 0.0192 & 0.0053 & 0.0175 & 0.0062 & 0.0268 & 0.0187 & -0.0503 \\
\hline & {$[0.800]$} & {$[0.501]$} & {$[0.860]$} & {$[0.539]$} & {$[0.831]$} & [0.709] & {$[0.796]$} & {$[0.685]$} \\
\hline Year fixed effects & Yes & Yes & Yes & Yes & Yes & Yes & Yes & Yes \\
\hline Industry fixed effects & Yes & Yes & Yes & Yes & Yes & Yes & Yes & Yes \\
\hline Observations & 841 & 841 & 841 & 841 & 841 & 142 & 142 & 142 \\
\hline Adjusted R-squared & $10.6 \%$ & & $10.9 \%$ & & & $-0.9 \%$ & $2.8 \%$ & $2.3 \%$ \\
\hline
\end{tabular}




\section{Table 8}

Multiple regression analysis on target premiums and relative wealth gains

The sample includes all SDC completed merger and acquisition deals between a U.S. public bidder and a U.S. public target announced between 1997 and 2008 . The deals start with at most $50 \%$ and result in $100 \%$ ownership by the bidder, where the book value of assets (BVA) of the target is at least $\$ 100$ million; the BVA of the target relative to the BVA of the bidder is at least 1\%; and the target founder information is available. In models (1) through (4), the dependent variable is the target's 3-day cumulative abnormal return around the deal's announcement, based on market model parameters. In models (5) through (8), the dependent variable, TPROP, is the target's relative wealth gain used in Kale et al. (2003). All variables are defined in the Appendix. Regressions include year and industry (two-digit SIC code main classifications) fixed effects. The $p$-values are in brackets and are based on heteroskedasticity-consistent standard errors. Coefficients denoted with ${ }^{\mathrm{a}},{ }^{\mathrm{b}}$, or $^{\mathrm{c}}$ are significant at the $1 \%, 5 \%$, or $10 \%$ level, respectively.

\begin{tabular}{|c|c|c|c|c|c|c|c|c|}
\hline & \multicolumn{4}{|c|}{ Target CAR $(-1,+1)$} & \multicolumn{4}{|c|}{ TPROP } \\
\hline & $(1)$ & (2) & (3) & (4) & $(5)$ & $(6)$ & $(7)$ & $(8)$ \\
\hline \multirow[t]{2}{*}{ Founder CEO } & 0.0056 & 0.0107 & 0.0115 & & -0.2447 & 0.8444 & 0.8835 & \\
\hline & [0.801] & {$[0.847]$} & {$[0.835]$} & & [0.579] & {$[0.536]$} & {$[0.517]$} & \\
\hline \multirow[t]{2}{*}{ FHC } & & & $-0.0092^{\mathrm{b}}$ & -0.0073 & & & -0.0018 & 0.0436 \\
\hline & & & {$[0.028]$} & {$[0.207]$} & & & {$[0.986]$} & {$[0.261]$} \\
\hline \multirow[t]{2}{*}{ Target's Tobin's Q net of FHC } & & & -0.0066 & -0.0511 & & & 0.1218 & -0.1485 \\
\hline & & & {$[0.301]$} & {$[0.707]$} & & & {$[0.441]$} & {$[0.927]$} \\
\hline \multirow[t]{2}{*}{ Target's Tobin's Q } & $-0.0082^{\mathrm{c}}$ & $-0.0085^{\mathrm{b}}$ & & & 0.0440 & 0.0341 & & \\
\hline & {$[0.073]$} & [0.019] & & & {$[0.313]$} & {$[0.702]$} & & \\
\hline \multirow[t]{2}{*}{ CEO age } & -0.0001 & -0.0002 & -0.0001 & -0.0034 & 0.0090 & 0.0132 & 0.0145 & -0.0600 \\
\hline & [0.890] & {$[0.874]$} & {$[0.895]$} & {$[0.333]$} & {$[0.668]$} & {$[0.596]$} & {$[0.563]$} & {$[0.141]$} \\
\hline \multirow[t]{2}{*}{ CEO CF right } & 0.0854 & 0.0786 & 0.0818 & 0.0198 & $-3.3337^{\mathrm{a}}$ & -4.9541 & -4.8050 & -0.1369 \\
\hline & {$[0.557]$} & {$[0.530]$} & {$[0.515]$} & [0.949] & {$[0.006]$} & [0.109] & {$[0.121]$} & {$[0.957]$} \\
\hline \multirow[t]{2}{*}{ Target's cash/assets } & 0.0673 & 0.0689 & 0.0679 & 0.1235 & -0.3938 & -0.4898 & -0.5403 & -2.4899 \\
\hline & {$[0.186]$} & {$[0.196]$} & {$[0.204]$} & [0.309] & {$[0.786]$} & {$[0.710]$} & {$[0.682]$} & {$[0.453]$} \\
\hline \multirow[t]{2}{*}{ Target's debt/assets } & $0.0794^{\mathrm{b}}$ & $0.0826^{\mathrm{b}}$ & $0.0831^{\mathrm{b}}$ & 0.1117 & 0.1402 & 0.4322 & 0.4574 & -0.2256 \\
\hline & {$[0.025]$} & {$[0.047]$} & {$[0.045]$} & {$[0.287]$} & {$[0.942]$} & {$[0.673]$} & {$[0.656]$} & {$[0.891]$} \\
\hline \multirow[t]{2}{*}{ Multiple class share structure } & -0.0353 & -0.0388 & -0.0395 & 0.0812 & -0.5426 & -0.5491 & -0.5801 & -0.3275 \\
\hline & {$[0.604]$} & {$[0.424]$} & {$[0.416]$} & {$[0.494]$} & {$[0.290]$} & {$[0.647]$} & [0.629] & {$[0.609]$} \\
\hline
\end{tabular}


Table 8 - continued

\begin{tabular}{|c|c|c|c|c|c|c|c|c|}
\hline & $(1)$ & $(2)$ & $(3)$ & $(4)$ & $(5)$ & $(6)$ & $(7)$ & $(8)$ \\
\hline \multirow[t]{2}{*}{$\ln$ (Bidder's total assets) } & 0.0048 & 0.0046 & 0.0046 & -0.0043 & 0.0201 & -0.0090 & -0.0106 & 0.2372 \\
\hline & {$[0.432]$} & {$[0.397]$} & {$[0.400]$} & {$[0.815]$} & {$[0.878]$} & {$[0.947]$} & {$[0.937]$} & [0.619] \\
\hline \multirow[t]{2}{*}{ Relative size } & $-0.0320^{\mathrm{b}}$ & $-0.0309^{\mathrm{a}}$ & $-0.0307^{\mathrm{a}}$ & $-0.1404^{\mathrm{a}}$ & -0.0725 & -0.0266 & -0.0149 & 2.3239 \\
\hline & {$[0.012]$} & {$[0.006]$} & {$[0.006]$} & {$[0.009]$} & {$[0.728]$} & {$[0.923]$} & {$[0.957]$} & [0.306] \\
\hline \multirow[t]{2}{*}{ Tender offer } & $0.0963^{\mathrm{a}}$ & $0.0994^{\mathrm{a}}$ & $0.0997^{\mathrm{a}}$ & 0.1369 & -0.6457 & -0.7356 & -0.7213 & -0.2075 \\
\hline & {$[0.001]$} & {$[0.000]$} & {$[0.000]$} & {$[0.118]$} & {$[0.116]$} & [0.199] & {$[0.208]$} & {$[0.784]$} \\
\hline \multirow[t]{2}{*}{$100 \%$ stock payment } & $-0.0357^{\mathrm{b}}$ & $-0.0347^{\mathrm{c}}$ & $-0.0350^{\mathrm{b}}$ & $-0.1221^{\mathrm{c}}$ & -0.7673 & $-0.7382^{c}$ & $-0.7559^{c}$ & $-1.9253^{\mathrm{c}}$ \\
\hline & {$[0.037]$} & {$[0.051]$} & [0.049] & {$[0.066]$} & {$[0.125]$} & [0.092] & {$[0.085]$} & {$[0.066]$} \\
\hline \multirow[t]{2}{*}{$100 \%$ cash payment } & 0.0439 & $0.0416^{\mathrm{c}}$ & $0.0417^{\mathrm{c}}$ & -0.0053 & -0.7340 & -0.7144 & -0.7075 & -0.7967 \\
\hline & {$[0.126]$} & {$[0.062]$} & {$[0.061]$} & {$[0.953]$} & {$[0.126]$} & {$[0.194]$} & [0.198] & {$[0.274]$} \\
\hline \multirow[t]{2}{*}{ Diversifying deal } & 0.0183 & 0.0222 & 0.0224 & $0.1132^{\mathrm{c}}$ & $-0.9370^{\mathrm{c}}$ & $-0.8363^{b}$ & $-0.8285^{b}$ & 0.4820 \\
\hline & {$[0.305]$} & {$[0.166]$} & {$[0.163]$} & {$[0.070]$} & {$[0.068]$} & {$[0.035]$} & [0.037] & [0.469] \\
\hline \multirow[t]{2}{*}{ Multiple bidders } & $-0.0643^{b}$ & $-0.0651^{\mathrm{c}}$ & $-0.0653^{c}$ & -0.0571 & -0.3743 & -0.3926 & -0.4025 & -3.1097 \\
\hline & {$[0.043]$} & {$[0.054]$} & {$[0.054]$} & {$[0.447]$} & {$[0.460]$} & {$[0.639]$} & {$[0.630]$} & [0.194] \\
\hline \multirow[t]{2}{*}{ Constant } & -0.0360 & 0.1028 & 0.0975 & 0.1579 & $3.5557^{\mathrm{c}}$ & 2.6480 & 2.3945 & 2.9074 \\
\hline & [0.659] & {$[0.245]$} & {$[0.278]$} & {$[0.681]$} & {$[0.061]$} & {$[0.226]$} & {$[0.280]$} & [0.627] \\
\hline Year fixed effects & Yes & Yes & Yes & Yes & Yes & Yes & Yes & Yes \\
\hline Industry fixed effects & Yes & Yes & Yes & Yes & Yes & Yes & Yes & Yes \\
\hline Observations & 841 & 841 & 841 & 142 & 841 & 841 & 841 & 142 \\
\hline Adjusted R-squared & $11.1 \%$ & & & $13.9 \%$ & $0.5 \%$ & & & $11.0 \%$ \\
\hline
\end{tabular}




\section{Table 9}

Multiple regression analysis on bidder gains

The sample includes all SDC completed merger and acquisition deals between a U.S. public bidder and a U.S. public target announced between 1997 and 2008. The deals start with at most 50\% and result in 100\% ownership by the bidder, where the book value of assets (BVA) of the target is at least $\$ 100$ million; the BVA of the target relative to the BVA of the bidder is at least 1\%; and the target founder information is available. The dependent variable is the bidder's 3-day cumulative abnormal return around the deal's announcement, based on market model parameters. All variables are defined in the Appendix. Regressions include year and industry (two-digit SIC code main classifications) fixed effects. The $p$-values are in brackets and are based on heteroskedasticity-consistent standard errors. Coefficients denoted with ${ }^{\mathrm{a}}{ }^{\mathrm{b}}$, , or $^{\mathrm{c}}$ are significant at the $1 \%, 5 \%$, or $10 \%$ level, respectively.

\begin{tabular}{lccc}
\hline & $(1)$ & $(2)$ & $(3)$ \\
\hline FHC & $-0.0054^{\mathrm{a}}$ & & $-0.0049^{\mathrm{a}}$ \\
& {$[0.000]$} & & {$[0.001]$} \\
Target's Tobin's Q net of FHC & 0.0386 & & 0.0380 \\
& {$[0.386]$} & & {$[0.524]$} \\
Relative change in Q & 0.0088 & & \\
& {$[0.647]$} & & \\
Lagged FHC & & -0.0047 & \\
& & {$[0.329]$} & \\
Target's lagged Tobin's Q net of lagged FHC & & 0.0207 & \\
& & {$[0.422]$} & \\
Target-initiated deal & & & 0.0244 \\
& & & {$[0.147]$} \\
Target-initiated deal $\times$ FHC & & & -0.0237 \\
& & & {$[0.117]$} \\
CEO age & & & \\
& & & \\
CEO CF right & & & \\
& & & \\
Bidder's debt/assets & & & \\
& & & \\
Multiple class share structure & 0.0007 & 0.0010 & 0.006 \\
Relative size & 0.0857 & {$[0.374]$} & {$[0.566]$} \\
& {$[0.304]$} & {$[0.265]$} & {$[0.162]$} \\
ln(Bidder's total assets) & -0.0232 & -0.0226 & -0.0315 \\
Bidder's cash/assets & {$[0.354]$} & {$[0.354]$} & {$[0.362]$} \\
& 0.0078 & 0.0053 & 0.0081 \\
& {$[0.292]$} & {$[0.503]$} & {$[0.334]$} \\
& -0.1153 & -0.0793 & -0.1197 \\
& {$[0.223]$} & {$[0.382]$} & {$[0.159]$} \\
& -0.0284 & 0.0088 & -0.0568 \\
& {$[0.897]$} & {$[0.339]$} \\
& -0.0083 & -0.0050 \\
& {$[0.294]$} & {$[0.380]$} \\
& -0.0089 & -0.0233 \\
& {$[0.633]$} & {$[0.240]$} \\
\hline
\end{tabular}


Table 9 - continued

(1)

(2)

(3)

\begin{tabular}{lrrr} 
Tender offer & 0.0059 & 0.0086 & -0.0059 \\
& {$[0.795]$} & {$[0.707]$} & {$[0.838]$} \\
$100 \%$ stock payment & -0.0153 & -0.0195 & -0.0234 \\
& {$[0.431]$} & {$[0.323]$} & {$[0.318]$} \\
$100 \%$ cash payment & 0.0241 & 0.0297 & 0.0179 \\
& {$[0.215]$} & {$[0.127]$} & {$[0.436]$} \\
Diversifying deal & 0.0238 & 0.0208 & 0.0287 \\
& {$[0.184]$} & {$[0.254]$} & {$[0.170]$} \\
Multiple bidders & -0.0175 & -0.0128 & -0.0132 \\
& {$[0.763]$} & {$[0.821]$} & {$[0.817]$} \\
Constant & -0.1281 & -0.1321 & -0.1070 \\
& {$[0.284]$} & {$[0.274]$} & {$[0.459]$} \\
Year fixed effects & & & \\
Industry fixed effects & Yes & Yes & Yes \\
Observations & Yes & Yes & Yes \\
Adjusted R-squared & 141 & 141 & 119 \\
\hline
\end{tabular}




\section{Table 10}

Median regression analysis on bidder gains, bidder buy-and-hold abnormal returns, and synergy returns

The sample includes all SDC completed merger and acquisition deals between a U.S. public bidder and a U.S. public target announced between 1997 and 2008 . The deals start with at most $50 \%$ and result in $100 \%$ ownership by the bidder, where the book value of assets (BVA) of the target is at least $\$ 100$ million; the BVA of the target relative to the BVA of the bidder is at least 1\%; and the target founder information is available. The dependent variable is the bidder's 3 -day cumulative abnormal return around the deal's announcement, based on market model parameters, in models (1)-(3); the bidder's buy-and-hold abnormal return from one day before the deal's announcement until the deal's completion, based on Fama-French-Carhart 4-factor model parameters, in models (4)-(6); and the 3-day synergy return around the deal's announcement, based on market model parameters, in models (7)-(9). All variables are defined in the Appendix. Regressions include year and industry (two-digit SIC code main classifications) fixed effects. The $p$-values are in brackets and are based on heteroskedasticityconsistent standard errors. Coefficients denoted with ${ }^{\mathrm{a}},{ }^{\mathrm{b}}$, or $^{\mathrm{c}}$ are significant at the $1 \%, 5 \%$, or $10 \%$ level, respectively.

\begin{tabular}{|c|c|c|c|c|c|c|c|c|c|}
\hline & $(1)$ & $(2)$ & $(3)$ & $(4)$ & $(5)$ & $(6)$ & $(7)$ & $(8)$ & $(9)$ \\
\hline \multirow[t]{2}{*}{ Founder CEO } & & -0.0026 & & & 0.0146 & & & 0.0024 & \\
\hline & & {$[0.681]$} & & & {$[0.605]$} & & & {$[0.718]$} & \\
\hline \multirow[t]{2}{*}{ FHC } & $-0.0040^{\mathrm{a}}$ & $-0.0039^{\mathrm{a}}$ & $-0.0053^{\mathrm{b}}$ & $-0.0270^{\mathrm{a}}$ & $-0.0274^{\mathrm{a}}$ & $-0.0261^{\mathrm{a}}$ & $-0.0030^{b}$ & $-0.0031^{b}$ & $-0.0040^{b}$ \\
\hline & {$[0.001]$} & {$[0.002]$} & {$[0.013]$} & {$[0.000]$} & {$[0.000]$} & {$[0.002]$} & {$[0.022]$} & {$[0.024]$} & {$[0.038]$} \\
\hline \multirow[t]{2}{*}{ Target's Tobin's Q net of FHC } & & 0.0009 & 0.0187 & & $-0.0219^{b}$ & $0.3817^{\mathrm{c}}$ & & 0.0003 & -0.0117 \\
\hline & & {$[0.653]$} & {$[0.719]$} & & {$[0.017]$} & {$[0.061]$} & & {$[0.881]$} & {$[0.798]$} \\
\hline \multirow[t]{2}{*}{ CEO age } & 0.0001 & 0.0001 & 0.0011 & 0.0018 & 0.0015 & $0.0085^{\mathrm{c}}$ & 0.0002 & 0.0002 & -0.0004 \\
\hline & {$[0.688]$} & {$[0.856]$} & {$[0.395]$} & {$[0.183]$} & {$[0.259]$} & {$[0.080]$} & {$[0.514]$} & {$[0.466]$} & {$[0.687]$} \\
\hline \multirow[t]{2}{*}{ CEO CF right } & $0.0682^{\mathrm{a}}$ & $0.0623^{\mathrm{b}}$ & 0.0732 & -0.0615 & -0.1250 & 0.4279 & -0.0048 & -0.0030 & -0.0496 \\
\hline & {$[0.009]$} & {$[0.026]$} & {$[0.435]$} & {$[0.605]$} & {$[0.324]$} & {$[0.240]$} & {$[0.863]$} & {$[0.921]$} & {$[0.542]$} \\
\hline \multirow[t]{2}{*}{ Target's cash/assets } & & & & & & & 0.0134 & 0.0138 & -0.0211 \\
\hline & & & & & & & {$[0.461]$} & {$[0.457]$} & {$[0.653]$} \\
\hline \multirow[t]{2}{*}{ Target's debt/assets } & & & & & & & 0.0105 & 0.0116 & -0.0476 \\
\hline & & & & & & & {$[0.412]$} & {$[0.371]$} & {$[0.255]$} \\
\hline \multirow[t]{2}{*}{ Multiple class share structure } & -0.0022 & -0.0033 & -0.0297 & $0.1383^{b}$ & $0.1476^{\mathrm{b}}$ & 0.0755 & -0.0023 & -0.0028 & -0.0081 \\
\hline & {$[0.876]$} & {$[0.821]$} & {$[0.420]$} & {$[0.036]$} & {$[0.024]$} & {$[0.597]$} & {$[0.878]$} & {$[0.856]$} & [0.801] \\
\hline \multirow[t]{2}{*}{$\ln$ (Bidder's total assets) } & 0.0006 & 0.0003 & 0.0043 & -0.0080 & -0.0069 & 0.0364 & -0.0028 & -0.0026 & 0.0010 \\
\hline & {$[0.702]$} & {$[0.873]$} & {$[0.572]$} & [0.293] & {$[0.358]$} & {$[0.219]$} & {$[0.117]$} & {$[0.154]$} & [0.888] \\
\hline \multirow[t]{2}{*}{ Bidder's cash/assets } & -0.0137 & -0.0227 & $-0.1786^{b}$ & $-0.1609^{c}$ & $-0.1571^{\mathrm{c}}$ & -0.2194 & -0.0132 & -0.0141 & -0.1163 \\
\hline & {$[0.485]$} & {$[0.245]$} & {$[0.027]$} & {$[0.071]$} & {$[0.076]$} & {$[0.479]$} & {$[0.559]$} & {$[0.536]$} & [0.101] \\
\hline
\end{tabular}


Table 10 - continued

\begin{tabular}{|c|c|c|c|c|c|c|c|c|c|}
\hline & $(1)$ & $(2)$ & (3) & $(4)$ & (5) & $(6)$ & $(7)$ & $(8)$ & $(9)$ \\
\hline \multirow[t]{2}{*}{ Bidder's debt/assets } & 0.0241 & 0.0219 & 0.0628 & 0.0370 & 0.0205 & 0.0255 & 0.0122 & 0.0139 & 0.0359 \\
\hline & [0.112] & {$[0.152]$} & {$[0.284]$} & {$[0.592]$} & {$[0.767]$} & [0.911] & {$[0.467]$} & {$[0.415]$} & {$[0.486]$} \\
\hline \multirow[t]{2}{*}{ Bidder's Tobin's Q } & $-0.0034^{\mathrm{a}}$ & $-0.0037^{\mathrm{a}}$ & 0.0013 & -0.0069 & -0.0059 & -0.0051 & $-0.0048^{\mathrm{a}}$ & $-0.0048^{\mathrm{a}}$ & 0.0005 \\
\hline & [0.009] & {$[0.008]$} & {$[0.822]$} & {$[0.242]$} & {$[0.345]$} & {$[0.817]$} & {$[0.001]$} & {$[0.001]$} & [0.924] \\
\hline \multirow[t]{2}{*}{ Relative size } & 0.0001 & 0.0013 & -0.0123 & -0.0240 & -0.0247 & $0.1677^{\mathrm{c}}$ & $0.0141^{\mathrm{a}}$ & $0.0142^{\mathrm{a}}$ & -0.0118 \\
\hline & {$[0.978]$} & {$[0.727]$} & {$[0.595]$} & {$[0.138]$} & {$[0.136]$} & {$[0.063]$} & {$[0.000]$} & {$[0.000]$} & {$[0.566]$} \\
\hline \multirow[t]{2}{*}{ Tender offer } & 0.0112 & $0.0120^{\mathrm{c}}$ & 0.0286 & -0.0129 & -0.0201 & -0.0100 & $0.0149^{\mathrm{b}}$ & $0.0156^{\mathrm{b}}$ & 0.0109 \\
\hline & {$[0.104]$} & {$[0.080]$} & {$[0.294]$} & {$[0.679]$} & {$[0.518]$} & {$[0.924]$} & {$[0.041]$} & {$[0.035]$} & [0.646] \\
\hline \multirow[t]{2}{*}{$100 \%$ stock payment } & 0.0028 & 0.0023 & 0.0011 & 0.0056 & -0.0043 & -0.0550 & -0.0054 & -0.0043 & -0.0282 \\
\hline & {$[0.590]$} & {$[0.664]$} & {$[0.960]$} & {$[0.813]$} & {$[0.857]$} & {$[0.507]$} & {$[0.342]$} & {$[0.447]$} & [0.136] \\
\hline \multirow[t]{2}{*}{$100 \%$ cash payment } & $0.0245^{\mathrm{a}}$ & $0.0255^{\mathrm{a}}$ & 0.0271 & $0.1036^{\mathrm{a}}$ & $0.0943^{\mathrm{a}}$ & 0.0985 & $0.0117^{\mathrm{c}}$ & $0.0124^{\mathrm{c}}$ & -0.0109 \\
\hline & {$[0.000]$} & {$[0.000]$} & {$[0.282]$} & {$[0.000]$} & {$[0.001]$} & {$[0.314]$} & {$[0.097]$} & {$[0.080]$} & [0.629] \\
\hline \multirow[t]{2}{*}{ Diversifying deal } & 0.0055 & 0.0065 & 0.0298 & $0.0488^{\mathrm{b}}$ & $0.0502^{\mathrm{b}}$ & 0.0318 & 0.0024 & 0.0030 & 0.0123 \\
\hline & {$[0.250]$} & {$[0.174]$} & [0.139] & {$[0.025]$} & {$[0.020]$} & {$[0.682]$} & {$[0.634]$} & {$[0.553]$} & [0.484] \\
\hline \multirow[t]{2}{*}{ Multiple bidders } & $-0.0318^{\mathrm{a}}$ & $-0.0317^{\mathrm{a}}$ & -0.0096 & 0.0297 & 0.0358 & -0.2904 & $-0.0201^{\mathrm{c}}$ & $-0.0189^{\mathrm{c}}$ & 0.0061 \\
\hline & {$[0.001]$} & {$[0.001]$} & {$[0.862]$} & {$[0.510]$} & {$[0.425]$} & {$[0.179]$} & [0.059] & {$[0.077]$} & [0.898] \\
\hline \multirow[t]{2}{*}{ Constant } & -0.0391 & -0.0362 & -0.1794 & -0.4320 & -0.3306 & -1.0051 & 0.0058 & -0.0026 & 0.0559 \\
\hline & {$[0.549]$} & {$[0.579]$} & {$[0.312]$} & {$[0.145]$} & {$[0.264]$} & {$[0.146]$} & {$[0.933]$} & {$[0.971]$} & {$[0.717]$} \\
\hline Year fixed effects & Yes & Yes & Yes & Yes & Yes & Yes & Yes & Yes & Yes \\
\hline Industry fixed effects & Yes & Yes & Yes & Yes & Yes & Yes & Yes & Yes & Yes \\
\hline Observations & 845 & 845 & 142 & 845 & 845 & 142 & 841 & 841 & 142 \\
\hline
\end{tabular}

